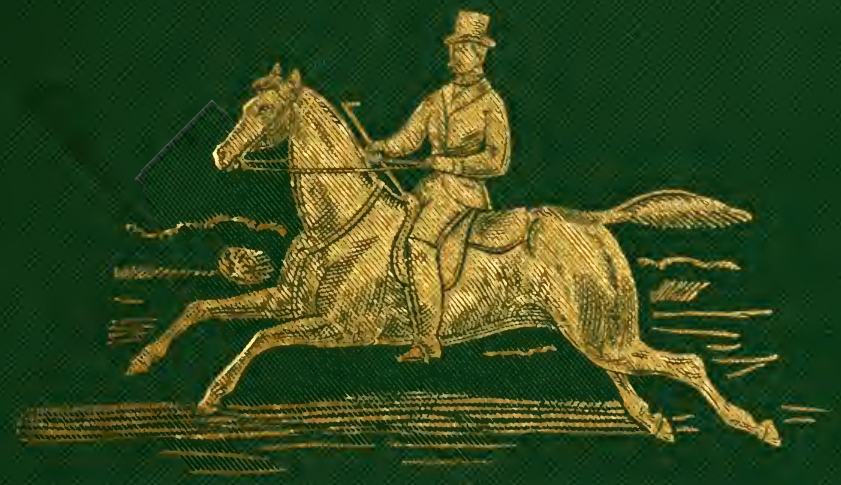




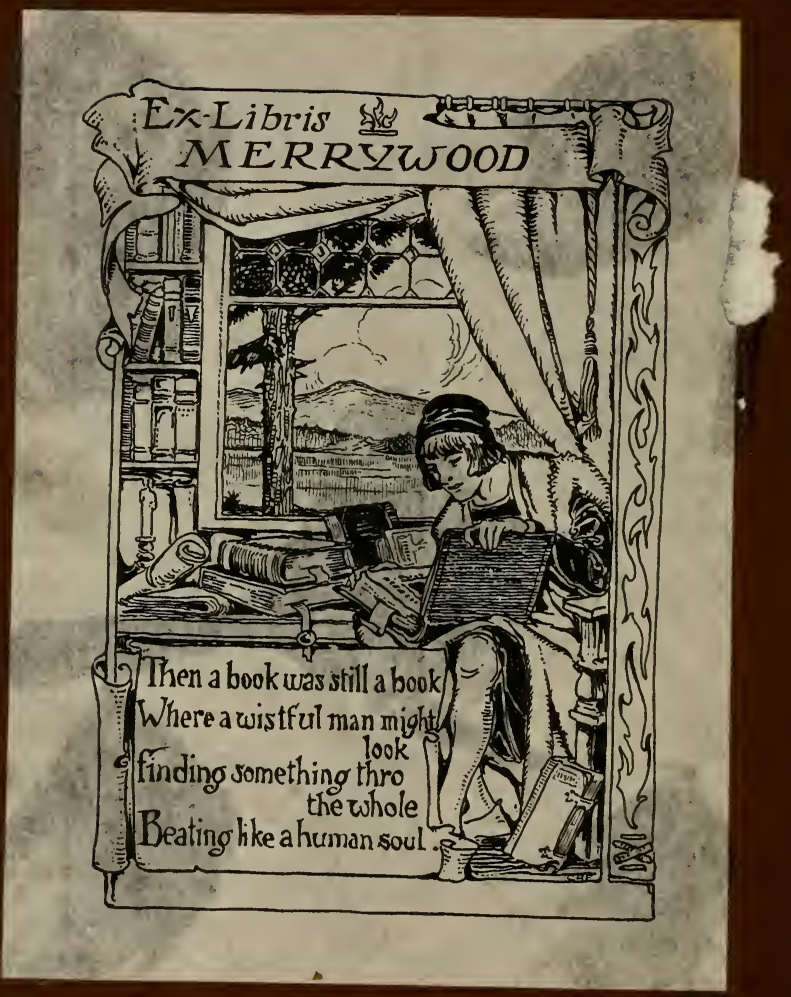




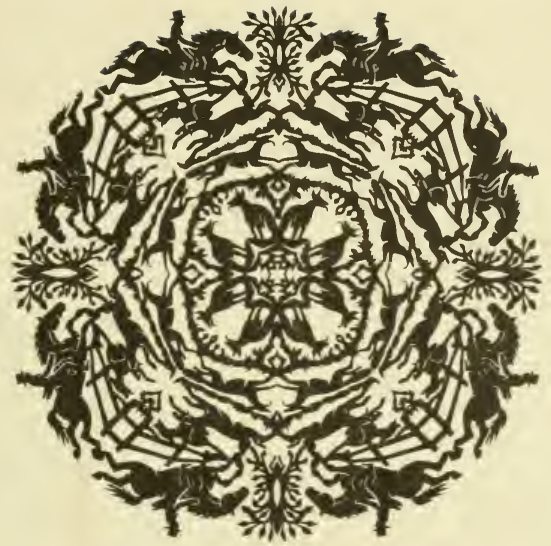

JOHN A.SEAVERNS 
$1+-2$<smiles>C1CCCC1</smiles> 
Whobter Family Library of Veterinary Medicine Cumnings School of Veterinary Medicine at Tufts University 200 Westboro Road North Graftion, MA 01536 

Slips for Librarians to paste on Catalogue Cards.

N. B.-Take out carefully, leaving about quarter of an inch at the back. To do otherwise would, in some cases, release other leaves.

ANDERSON, EDWARD I. ON HORSEBACK : IN the School and on the Road. By Edward L. Anderson. New York: Henry Holt \& Co., I882. I2mo, pp. 2 I8.

ON HORSEBACK: IN THE SCHOOL AND ON THE Road. By Edward L. Anderson. New York: Henry Holt \& Co., I882. I2mo, pp. 218.

HORSE. On HoRseback: In the School and on the Road. By Edward L. Anderson. New York: Henry Holt \& Co., I882. I2mo, pp. 2 I8.

SPORTS. On HoRseback: In the School AND on the Road. By Edward L. Anderson. New York: Henry Holt \& Co., I882. I2mo, pp. 218. 





\title{
ON HORSEBACK
}

\section{IN THE SCHOOL AND ON THE ROAD}

\author{
BY \\ EDWARD L. ANDERSON \\ AUTHOR OF
}

"HOW TO RIDE," AND OF "A SYSTEM OF SCHOOL RIDING FOR HORSES."

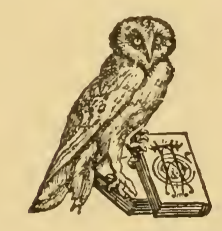

NEW YORK

HENRY HOLT \& COMPANY I 882 



\section{PREFACE.}

This book is a welding together, re-arrangement and partial re-writing of two predeccssors. I published the first, "How to Ride," in London, during a temporary residence abroad. It was my intention to bring out an edition of it in this country, but I was prevented doing so by the action of the Orange Judd Company, which issued my book in a mutilated form, incorporated with matter by some other hand, under the title of "Riding and Training Saddle Horses."

The second book, called "A System of School Training for Horses" (about to appear in London), which was intended as a sequel to 
its predecessor, would prove too technical for readers who have not had the instructions of the primary work, and as the unauthorized edition was neither complete nor credited to me, I have thought best to meet the case by the complete re-arrangement offered herewith.

In these pages I have not only endeavored to render my meaning clear by full explanations of the theories advanced, but have also incorporated in the index a glossary of terms used.

Cincinnati, March 25, 1882. 


\section{CONTENTS.}

Preface................................. 3

INTRODUCTION ......................... 7

PART I.

ON THE ROAD.

CHAPTER

I. How to use A Horse............... 2 I

II. Equipments...................... 26

Bits and Martingales.............. 27

III. Getting into Place............... 3 I

To Mount.................... 3I

The Seat....................... 34

The Reins..................... 39

IV. Horse Gymnastics.............. 4I

Exercises for the Seat.............. 43

For the Balance................. 45

For the Legs and Feet............. 47

To Mount..................... 48

To Dismount................... 50

General Exercises................ 5 I 
CHAPTBR PAGE

V. Hands and LEgs................. 53

VI. THE WALK AND THE TROT............. 63

VII. The Gallop..................... 69

VIII. LEAPING ..................... 72

IX. Vices, Tricks, and Faults........... 77

PART II.

IN THE SCHOOL.

I. The Equilibrium.................. 86

II. Suppling the Foremand.............. 9

III. Suppling the Croup.............. II

IV. To BACK..................... I2I

V. The Passage................... 129

VI. The Piaffer.................... I32

VII. To Back at the Piaffer ............ I 136

VIII. Changes in the Gallop.............. I39

IX. To Halt in the Gallop............. I 47

$\mathrm{X}$. The Gallop in Place................ I5O

XI. To Back at the Gallop............. I54

XII. The Spanish Trot................ 158

XIII. Traversing in the Passage........... r65

XIV. Traversing at the Gallop.......... I 72

$\mathrm{XV}$. Voltes and Pirouettes............. I 76

XVI. Teaching to LeaP................ I 83

XVII. General Notes ................. I97

XVIII. When Ladies RIDE................ 208 


\section{INTRODUCTION.}

IT is fit that I should offer some explanation for advocating the school system of training, since it is generally regarded as something fanciful and useless, if not positively mischievous.

First, a few words concerning the importance of a thorough method in the training of horses for the saddle, and then I shall answer, as far as I am able, the objections that are raised against the systems of the schools.

Whether it be in the field, upon the 
road, or in the troop, the rider must follow some sort of method in the management of his horse.

Every horse that can be ridden is to some extent schooled, as we understand it in the manege, and the more amenable he is to the will of the rider the more nearly the object of every system of the schools has been obtained, no matter whether his trainer knew or was ignorant of what he was effecting or how it was brought about.

Teaching the horse to turn to the right or to the left, driving him forward with the heels, and measuring his speed and perfecting his paces, are things that every rider endeavors to accomplish, and these are, all of them, primary principles of the schools. 
Is it not well to go further, and to teach the horse a ready and precise obedience to the every wish of his rider? For the object of school methods is simply to acquire control over the horse under all circumstances, and the various movements practiced are for the purpose of rendering him quick and willing to answer the demands of his rider.

As to the uselessness of this training and its results, where shall the line be drawn between the highly-trained charger and the awkward, stubborn colt? It may not be necessary for the gentleman who follows the hounds or takes a ride in the park, to move about at the traverse or to exhibit the action of his horse in the Spanish trot, but if he can make his horse perform these movements he will have 
an animal that is the safer and pleasanter to ride, by reason of his lightness and obedience.

Nor do I see any grounds for the principal objection against school training, that it decreases the speed of the horse. It is true that in the balanced movements of the manége the horse is made to step short, both to retain the balance in the direct line and to enable the animal to make short and sudden changes of direction. But to enable a horse to carry himself in the equilibrium of the school his every muscle must be suppled and strengthened, and I hold that it is self-evident that when the horse is permitted to extend himself his speed would be the greater and his going the stronger for his training. This is evi- 
denced, too, in the buck-jumps and the other high movements of the manegere. In the limited area of the riding-school, the trained horse will take leaps that would do credit to the most active hunter, while the latter would not find room to turn in his lumbering gallop. Why this suppleness and strength should decrease the natural speed of the horse I cannot conceive, and I think that the idea originated in the belief that the short step of the balanced horse is the natural result of a cramped training-ground, and not, as is the fact, purposely brought about by strengthening and suppling the animal, so that he may carry himself lightly.

It should be observed that in modern school-riding, the forces of the horse are brought into balance, so that no undue 
weight falls upon either extremity. Thus another objection to the system is groundless.

To kick a horse along and to pull him to the right or to the left by sheer force, is, to a certain extent, riding, and I suppose will satisfy the requirements of most horsemen, but it is not the highest standard of horsemanship, and the more it is improved upon the better for the horse and his rider.

I think that it is a mistake to place children of tender age upon horseback, for there is nothing to be gained in such a course that will compensate for the risk of injuries they may receive. An active man may learn to ride well at any age; and a bold boy of fourteen, who comprehends the system upon which he is taught, 
will in six months become a better horseman than the lad who has been riding six years according to his own ideas. It is not given to all men to excel in riding; courage, activity, a perfect temper, and aptitude for the exercise are requisite for the acquirement of the highest skill. But a knowledge of a proper method will give to every one comparative immunity from the dangers that attend horsemanship. A schooled horse, confiding in his master and obedient to the spur, is not apt to try his powers in rebellion; and when in hand and properly gathered he will recover from a mistake that might otherwise prove disastrous.

It is not necessary that every man should learn or that every horse should be taught all the movements of the manége. 
It will be enough for all practical purposes of ordinary riding if the horse carries himself in equilibrium and obeys the indications of the hand and legs, and the rider has a seat that permits him to make a measured use of the aids under every circumstance of motion and action. But that which remains to make a thorough horseman and a schooled horse is so little, that I have here given a method for those movements of the manége that have been found most useful in giving the horse control of his powers and in making him obedient to the will of his rider.

There can be no objection to a rider becoming skillful in the management of his horse, or to the horse being rendered obedient to his master's wishes. A perfectly schooled horse is a horse perfectly fitted 
for any use; and a rider who has a seat that permits him to apply the aids in the vigorous movements of the manege is prepared for any emergency, upon the road or in the field.

There are those who hold the opinion that no one can learn to ride from the rules laid down in books. How is one to learn to ride? From the first there is little that the beginner must not learn, from rule or from example, and, according to his aptitude for the exercise, he improves in skill by practicing that which he has acquired by observation or through instruction. The general rules of the art are the results of ages of experiment, and it is doubtful whether a man would ever, by his unaided efforts, reach any great proficiency in riding. One may consider himself to be self- 
taught; but the fact is that nearly everything he knows about riding is derived from imitating those who have in some way gained a knowledge of proper usages, and afterwards by deducing natural sequences from these established rules.

If the pupil is fortunate enough to have the personal instruction of a skilled master, he will, perhaps, learn more rapidly than by following the precepts of a book. But he is much more apt to find a proper system in some work that has received the approbation of the authorities upon the subject than in the instruction he receives from grooms and self-styled masters. The instructions given to the recruits in the military riding-schools are, for the greater part, a repetition by the instructor of the printed rules, which he must learn by rote. 
I have known many good riders who owed all they knew in the art to a study of the intricate laws laid down by Baucher. I have many times taught movements to horses by following the directions of competent writers, and I have never failed in accomplishing that which I undertook.

I wrote How to Ride, and I write this work, from a love of my subject, and because I am convinced that a pupil may learn to ride and to school a horse from books.

While I do not think that this book can in any sense be considered a compilation, I wish to say that I have studied the works of nearly all the modern writers upon my subject and have had instruction from several professional school-riders; but I have also had the experience of many 
years in training my own horses, and I believe that in every chapter I have presented original ideas, not inconsistent, I hope, with proved methods. 
P A R T I.

O N THE ROAD. 



\section{CHAPTER I.}

HOW TO USE A HORSE.

THE whip and the spur are necessary aids in the education of the horse, and in compelling his obedience after he has been trained. The whip should be seldom used to inflict punishment, the spurs never. For instance, if a horse rears, the spurs must be employed to force the action of the hind-quarters, and so to drive him forward; but having brought about that result, they must not be thrust into him to punish him for rearing. The horse is to be taught that 
the spur is applied to make him bring certain forces into action, and when used with discretion he will respond to it; but unnecessary strokes with the spur will rouse his resentment, and he will stubbornly refuse to obey its indications. It serves no good purpose to irritate a horse, as he will never yield while angry. A contest between horse and rider should always be avoided, for, in addition to the chances that the former will prove the victor, a high-spirited animal may be made incurably vicious, when by milder treatment he could be subdued without endangering his usefulness. A rebuke in a harsh tone of voice will generally suffice to correct a horse, and he will not know how to resent it. The best way to control the horse is through firmness 
and kindness, but timidity is worse than severity in inducing vice.

The young horse soon becomes tractable, and as long as his temper is unruffled he desires to do that which is required of him. Until the spirit of rebellion is awakened, he is as anxious to avoid the perils of battle as his master should be. If upon an occasion he declines to perform some movement that is required of him, let his attention be turned to that which will please him, and his obedience in this will induce his obedience afterwards to the first demand. To give up to him after a battle will confirm his - obstinacy, but he will soon forget his unnoticed defiance. Under proper treatment he will in time yield to the will of his master without dreaming of resistance. 
The story of Tarleton taming his savage steed with bloody spurs, and the vivid descriptions of the manner in which the Mexican breaks the spirit of the mustang, may pass to adorn the pages of a romance, or to heighten the interest of a traveler's tale. But, aside from the cruelty and peril of such methods, there remains the fact that horses so broken submit for the time only, and the struggle is to be repeated more or less often. Except in those rare cases of horses naturally vicious, and they are lunatics, fear is the mastering passion of the horse. It is cowardice that drives him to desperate resistance against the sway of his master; the effort that is successful in ridding him of his tyrant suggests his favorite vice. 
I do not, in these remarks, have reference to those tricks that a horse acquires through the inexperience or the timidity of a rider, for, like all cowards, the horse loves to play the bully. As he will seldum take the liberty of practicing these upon a resolute man, it is not necessary to point out to his victims what course to pursue.

If the horse is taught to calm his fears at the sound of the voice of man-if he is never ill-treated, in or out of the stable -if he does not perceive timidity upon the part of his masters, and if, with all these conditions, he is given plenty of air and exercise, he will never show vice. 


\title{
CHAPTER II.
}

\author{
EQUIPMENTS. \\ The Saddle.
}

The tree, of the pattern known to the world as the English saddle, should be selected and covered to permit the rider, with his peculiarities of figure, taking an erect position from his buttocks. It must be large enough. A saddle that is too short prohibits a proper seat, but the rider may be comfortable in a saddle that is larger than is absolutely required.

The panel should be stuffed to fit the horse when the saddle is placed as far for[26] 
ward as will admit of the free use of the shoulders.

The stirrups should be roomy, with a broad tread, and of medium weight. The holes of the leathers should be punched to correspond, and numbered. The leathers should be attached to the saddle by a spring-bar; the bar that works upon a hinge is the best.

\section{Bits and Martingales.}

There is no combination-bit that will supply the place of the "curb and snaffle" of the double bridle. The effects of both of these are required in schooling and in riding the horse. And, although they are never to be used simultaneously, the action of one must often follow that of the other 
in a manner that precludes the substitution of a single bit.

The snaffle should be buckled to the under check-pieces of the bridle, so that it will lie up in the corners of the mouth without pressure.

The mouth-piece of the curb should be of proper width. It is to rest upon the bars of the mouth; for which reason the port should be of a size to hold the tongue, but it must not be high enough to torture the horse. The cheek-pieces should be from one and a-half to one and three-quarters inches in length from the center of the mouth-piece to the fastening of the curbchain hook. The branches should be from four and a-half to five inches in length, according to the power required.

The curb chain should hang loosely in 
the groove of the chin, and its width should depend upon the size of the groove.

When the bits have been fitted, and the horse has become accustomed to them, they should not be shifted.

There is little to be said in favor of martingales. The martingale tends to keep the snaffle in place upon a young or a tender-mouthed horse, who throws up his head to a heavy hand; but its intervention denies that delicate tension on the mouth that we are seeking; and it will not cure, although it may restrain, the habit that seems to demand its use. The standing martingale, buckled into the bit, is a cruel instrument that may throw the horse. The least objectionable of all the martingales is that attached to a nose-band. But 
this, to be of any service, confines the head of the horse too much for him to make the necessary efforts to recover from a mistake. None of these contrivances will prevent a horse rearing, and the lastnamed will answer all the purposes that the others may.

I believe that every horse is susceptible of being taught to carry his head in position, and I shall endeavor to show how this end may be brought about. 


\title{
CHAPTER III.
}

\author{
GETTING INTO PLACE.
}

\section{To Mount.}

FACING the near side of the horse, stand opposite his girth; take the reins in the right hand, and with it grasp the pommel of the saddle, shortening the reins until you feel the mouth of the horse.

Hold the stirrup with the left hand, and insert the left foot; seize a lock of the mane in the left hand, close to the crest of the neck, turning the thumb uppermost.

Rise in the stirrup, aided by both hands, until the left leg is straightened; 
carry over the right leg, and sink into the saddle.

When the seat is obtained release the holds upon the mane and pommel, and pass the reins into the left hand.

After the left hand has seized the mane the horse cannot prevent the rider reaching his seat; and the rider firmly establishes himself before he withdraws the support of either hand.

There is no difficulty, for one who is not infirm, to mount in this way, and the only objection that can be made to it, so far as I can see, is that by a "cow-kick" the man standing at the girth may receive an injury. But this is a rare vice, and a horse that kicks is dangerous to approach, for mounting or for any other purpose ; so that it is hardly worth while to abandon a 
system that is otherwise excellent, because it does not apply to a very small class of vicious brutes, that should not be used for saddle under any circumstances.

On the other hand, nearly every horse will paw with a fore-foot, if at all impatient, and he who stands in front of the shoulder of a horse is not secure from injury. Among the other disadvantages of the generally adopted method I may mention the following :-

I. The rider, standing in front of the shoulder of the horse, may be overset by a forward movement; and this danger is greatly increased after the foot is put into the stirrup.

2. The left hand, entangled and held in the hairs of the mane, cannot use the reins. 
3. The drag upon the cantle of the saddle must, in all cases, disturb its position, and may cause it to turn.

4. The right arm fastened to the cantle of the saddle prevents the right leg passing over the back of the horse.

5. To pass the right leg over the horse the right arm must be removed; thus taking away the principal brace of the body at the most critical time, and allowing the body, in case of any movement, to fall backwards towards the shoulder of the horse.

6. The absence of a reason for any one motion in the method.

\section{The Seat.}

Upon the seat depends the security of the rider, not only as regards his remain- 
ing upon the horse, but in permitting him to use that lightness and delicacy of touch that is required to manage and control the horse. It has often been said that this desired lightness of touch is a rare gift, wholly denied to strong men. But if a man have a seat that is independent of any support from the reins, he may acquire a light touch upon the mouth of the horse as readily as he may make a fine stroke with a pen.

As I have said, each man has a seat peculiar to himself, and that will be his seat for all purposes, whether in the field, upon the road, or in the school.

It will be obtained in the following manner :-

After having reached the saddle, disengage the left foot from the stirrup. Then 
bearing the weight of the body upon the buttocks, make the inner sides of the thigh, from the knee up, grasp the saddle. The body must be held erect, the shoulders thrown back, and the chin drawn in; and the elbows should be carried close to the sides.

The legs, from the knee down, should hang without stiffness, and the feet will, without effort, find their proper place, parallel with the body of the horse.

The length of stirrup-leather will be found when the tread of the iron strikes the heel of the boot immediately above the junction of the sole. The toes will be raised and inserted in the stirrups as far as the balls of the feet.

The stability of the seat is dependent upon the weight of the body, the balance, 
and the grasp of the thighs. The erect seat upon the breech, that we have described, permits the body to make, most readily, those motions that are necessary for preserving the perpendicular application of the weight, and for keeping the balance. The strongest hold upon the saddle possible is with the inside of the thighs.

There should be no pressure upon the stirrups; for this would relieve the weight, disturb the balance, and force the grip of the thighs. It is no argument in favor of riding upon the stirrups that the horsemen of the East carry their knees up to the pommel of the saddle, for the Mexicans, who are better riders, extend the leg to its full length.

It is in spite of bad systems that 
these peoples who live on horseback become skillful in the management of their steeds. Because a circus performer standing upon one leg keeps his horse under circumstances that would prevent a poor rider from keeping in his saddle, it does not follow that the proper way to ride is upon one leg.

The seat having been found and the stirrups having been adjusted, no changes should be made for the different circumstances under which the rider will be called upon to exercise his skill. It is bad art when the principles are not suited to every emergency; and the seat that has been found to be that in which the center of gravity can best be preserved in the high airs of the manége, where the horse makes the most violent movements of the fore- 
hand and of the croup, should answer all requirements.

\section{The Reins.}

The beginner will use the reins of the snaffle only. He will take a rein in the grasp of each hand, the loose end passing under and held by the thumb, at a length that will give him command of the mouth of the horse.

In teaching the horse the changes of direction, as is described in the chapter upon "Hands and Legs," one hand will hold the curb, the reins divided by the little finger and grasped by the thumb; while the snaffle-reins will be held above those of the curb, divided by the breadth of the other hand.

There are various ways prescribed 
for holding the reins in riding the trained horses, but I prefer the following method :-

In the left hand: the curb-reins divided by the little finger; the snafflereins divided by the middle finger; the ends of both sets carried up through the hand and secured by the thumb, which should be uppermost and pointed to the ears of the horse. By bending the wrist to the right so that the knuckles come uppermost, the head of the horse will be carried to the right, and the change made in that direction. By bending the wrist to the left, so that the finger-nails come uppermost, the horse will be turned to the left. There should never be tension upon the two bits at the same time. The horse should be ridden upon the curb; 
the snaffle will be used to fix the height of his head, and, occasionally, to take the place of the curb to freshen the mouth.

The right hand will be carried upon the loose ends of the reins to assist the left. 


\section{CHAPTER IV.}

HIORSE GYMNASTICS.

THE following exercises will be found of great service in giving strength to the seat, in aiding the balance, in teaching the habit of regaining a lost position without disturbing the tension of the reins, and in giving ease and grace to all the motions of the rider.

When so indicated, these movements will be made from the position prescribed for " the seat." 


\section{Exercises for the Seat.}

\section{I.}

In the seat, with the arm hanging motionless by his side, let the pupil take away one thigh from contact with the saddle and bring it back into its place, with the point of the knee turned in as much as possible, the movement being made by a rotation of the hip joint. This should then be done with the other leg.

\section{II.}

From the seat, and the rest of the body in quiet, raise both knees to meet above the pommel of the saddle, and 
bring them back to the saddle, making the inner sides of the thighs take as many points of contact as possible.

\section{III.}

In the seat, keeping the thighs close to the saddle, let the pupil lean back until his shoulders touch the rump of the horse; then let him quietly recover his erect position.

\section{IV.}

In the seat, keeping the buttocks in the saddle and the thighs in place, let the pupil lean forward and slightly to one side until one of his shoulders touches the crest of the horse. Then let him slowly recover his position. 


\section{V.}

In the seat, let the body sway forward, to one side, to the rear, to the other side, and then into position; then reverse the movement.

\section{VI.}

Lose the seat to the right, and without aid from the hands bring the body back into the saddle by a quick turn of the buttocks; then make the movements to the other side. This should be practiced at the walk, at the trot, and at the gallop.

For the Balance.

\section{I.}

In the seat, the arms hanging without stiffness, carry the right leg over the 
pommel to the left side; then carry both legs over to the right; then come back to the seat by carrying the left leg to its place.

\section{II.}

In the seat, carry the right leg over the pommel to the left side; then work the body upon the buttocks as a pivot until the face is to the rear. Carry the left leg over, then the right leg, and work the body upon the buttocks as a pivot until the face is to the front. Resume the seat by carrying the left leg over the pommel to its place; then reverse the movement. 


\section{For the Legs and Feet.}

\section{I.}

In the seat, keeping the knees fixed, bring the lower part of first the one leg and then the other, as high up on the side of the horse as is possible, without either touching the horse or moving the knee. This movement should be done at the walk, at the trot, and at the gallop, so that the rider may have perfect control of the action of the legs in directing the movements of the croup.

\section{II.}

In the seat, the legs hanging without stiffness and the rest of the body quiet, 
rotate, first the one foot and then the other, from the ankle joint, with an outward and then an inward movement. The improvement in this exercise may be measured by the facility with which the pupil can gain his stirrups by the action of the feet only.

\section{To Mount.}

Standing at the shoulder of the horse, facing the near side, with the left hand seize a lock of the mane close to the crest, the hairs passing down through the hand, the thumb uppermost.

With the right hand grasp the pommel of the saddle, the fingers under the tree, the thumb extended towards the ground.

Leave the ground with a spring and 
take the weight of the body upon the arms until the fork is level with the withers of the horse, resting a moment in this position.

Carry the right leg over, and sink quietly into the saddle.

Release the holds upon the mane and the pommel.

To those who have never tried it, this movement appears to be difficult. It is, in fact, very easy, and should be accomplished after a few trials by any one who is active enough to undertake riding. It should be performed at the walk, at the trot, and at the gallop. At the gallop care must be taken not to carry the body over too much in putting the right leg across the horse, nor need the body be carried so 
high as when the horse is at rest, nor is the momentary stop to be observed.

\section{To Dismount.}

Seize the mane and pommel as in mounting. Bear the weight upon the straightened arms as the right leg is brought over to the left side. Hold the body for a moment perpendicularly to the side of the horse, the whole weight being supported by the two arms. Drop gently to the ground at the shoulder of the horse. This may be done at the gallop, by avoiding the momentary rest and coming down prepared to take a few steps with the horse, after which the holds upon the mane and pommel should be released. 


\section{General Exercises.}

\section{I.}

From the seat, grasping each side of the fore-part of the saddle, bear the weight of the body upon the extended arms, turning the balanced body first one way and then the other.

\section{II.}

From the seat, grasping each side of the fore-part of the saddle, throw the body forward upon the slightly bent arms towards the neck of the horse; and throwing up the legs in rear, cross them, and come into the saddle faced to the rear. 


\section{III.}

From this position, place the palms of the hands upon the rump of the horse, and performing a movement similar to the above, come into the saddle faced to the front. 


\section{CHAPTER V.}

\section{HANDS AND LEGS.}

THE beginner should be mounted upon a quiet horse, so that the mistakes a young rider necessarily makes will not bring about disasters that would destroy all taste for the exercise.

The snaffle-reins should at first be used, one held in each hand, at a length that will give control over the horse without confining the head of the animal to interfere with his movements.

The horse will be induced to move forward by a slight pressure of the rider's 
heels, while the hands will yield sufficiently to permit the horse to answer this demand. As soon as the horse moves forward the hands will take a slight feeling upon the bit to measure the rate of speed, but not strong enough to bring the horse to a halt. Practice only can show the rider how great this tension upon the reins should be, but the least force that will produce the desired effect is always the best.

If the horse hangs back or decreases his speed the heels must be pressed in to drive him forward, and the hands should be ready to increase or to lessen the tension upon the reins as the circumstances may dictate.

In turning to the right or to the left, the rein of the side to which the change of direction is to be made will be drawn 
towards the rider's body and the opposite heel will be pressed in to bring up the hind quarters upon the new line. The other, or outside rein will steady the horse in the movement.

When the rider desires to come to a halt he will first press in his heels, to induce the horse to carry his hind-legs in under the body, and immediately after he will raise up and draw in both reins to check the forward motion, yielding the hand the moment the horse comes to a halt.

The rider should be satisfied to practice these exercises at the walk until he finds that at that pace he has perfect control over his horse.

When the rider has acquired a seat that is not easily disturbed, and has dis- 
covered the tension of the reins that permits the horse to move freely and yet controls him, he may gradually increase the speed. But it is not advisable that he should take a rapid pace until he has learned how to collect his horse and to use both hands and legs with quickness and precision at a moderate speed.

After he has obtained a seat that does not depend upon the support of the reins, the rider should use the double-bridle. The curb-reins will then be held in the left hand, divided by the little finger, while above them the right hand will hold the reins of the snaffle-bit, divided by its breadth.

The first lessons in the double-bridle will be given at the halt. The hand should be held at such an elevation as will permit 
the horse to carry his head at the height that gives him the greatest comfort. Then by gentle vibrations of the curb-reins the horse will be induced to bring his head into a vertical position, and to yield his jaw, when he should be rewarded by the rider making a corresponding concession by lessening the tension on the bit. When the curb-reins are brought into play, the rider should close his legs against the sides of the horse to keep the hind-quarter up in position and to prevent a retrograde movement.

The horse should then be put into a walk, and while the closed heels of the rider keep up the movement the hands should, through the curb-reins, induce the horse to bring his head into position and to yield the jaw by the vibratory motions 
before described, releasing the tension upon the reins the moment the horse obeys the pressure of the bit.

In this way the horse will be ridden in progressive lessons at the walk, at the trot, and at the gallop, the rider always demanding the relaxing of the jaw and the maintenance of the speed, but never keeping a steady tension upon the reins.

Should the horse be heavy in the forehand and inclined to bear upon the hand, he should be made to carry himself light by short pulls upon the snaffle-reins, held in the right hand, from below upwards. But the active resistance of the horse should be overcome by the light play of the curb-reins.

The effects of the bit should be aided by the rider's heels. That is, the hind legs 
of the horse will be brought under him by a pressure of the heels preparatory to a halt or when the speed is to be decreased; and the bearing upon the mouth should always be of the lightest, and never constant, but ready to yield the moment the horse gives to the play of the bit.

During these lessons the rider should endeavor to keep his horse collected, so that the movements of the horse will be light and easy to govern.

As the legs act upon the forces of the croup, and as the hand directs the forces of the forehand, it will be seen that the rider can bring about a union and balance of these forces and obtain immediate and distinct control of the mass.

This union and balance of the forces is known as the equilibrium, and is 
treated at length in the first chapter of the second part of this work. In turning to the right or to the left the hand holding the curb-reins will be carried slightly, by a bend of the wrist, to the side of the new direction, so that the rein will press against the opposite side of the horse's neck to bend the forehand; the outside heel will bring up the croup upon the new line.

As soon as the forehand turns the hand will take an equal pressure upon both sides of the mouth, for the moment, to insure the direction, and the legs will straighten the croup when it arrives upon the line.

Between hand and legs the forces of the horse must be at all times kept collected, and the young rider will endeavor 
to keep these aids ready to correct those errors in movement that the more skillful rider will anticipate and prevent.

'The rider must make the horse understand that he cannot pass beyond the limit put by the hand without bringing pain upon himself, but that so long as he is obedient to the bit, he will find comfort. To this end the hand will firmly resist any attempts of the horse to go beyond the fixed limit, but it will make a concession whenever he yields his opposition.

If the speed is to be increased, the legs will act upon the croup and the hand will give more freedom to the forchand.

If it is desired to moderate the speed, the forces of the forehand will be brought back, by an increased tension upon the reins; and when they are brought back to 
a point where they balance the forces of the croup a halt is brought about.

The rider must bear in mind that to have his horse light in hand and amenable to control the horse must be collected, yielding to the bit and ready to answer the pressure of the heels. But if the horse is permitted to bear upon the hand, or to hang back, he becomes heavy, the equilibrium is lost, and the horse is no longer ready to give instant obedience. 


\section{CHAPTER VI.}

THE WALK AND THE TROT.

IT is not necessary, nor is it desirable, that the tight grip of the thighs should be maintained while at the walk. The gait is so smooth that the weight and the balance will serve to keep the rider in his seat, and the knees being in position the thighs may instantaneously take their hold in case of a sudden start of the horse.

But this ease should never degenerate into negligence, and as a horse is more apt to stumble at a walk than at a quicker gait, the rider must never permit his atten- 
64 THE WALK AND THE TROT.

tion to be taken from his horse. The horse should be kept constantly in hand, particularly after any great exertion that has called upon his strength, for he is much less able to recover from a mistake when he is tired, and he feels the fatigue less when he is kept roused. In going down hill he must have liberty enough to permit his body conforming to the slope of the ground, so that he may extend his step safely.

For the trot the horse must be kept level and light, between the application of the hand and legs. The speed will be restrained by the first or augmented by the latter, at the will of the rider, whose efforts should be so directed as to give a regularly-cadenced gait of equal action, in the highest equilibrium possible. 
The height and brilliancy of movement in the trot may be governed by the application of first the one and then the other spur, assisted by the rein of the same side, as the opposite fore-leg of the horse is raised to step off. In this way it may be developed into the Spanish trot of the manége.

In the trot the rider should sit erect, with the shoulders thrown back, and the thighs close to the saddle.

If the rider rises to the trot the constant shifting of the weight will greatly interfere with the equilibrium of the mass, but it is not necessary that the horse should get out of hand or be permitted to bear upon the bit.

The rider should take no support from the bit, but should hold his hand so that 
it will be independent of the motion he allows his body to make.

To rise in the trot the rider will make use of the knees to secure the seat and allow his body, slightly sustained by the stirrups, to be thrown up by the motion of the horse, letting his weight sink back into the saddle in time to take the next impetus of the gait. The shoulders should be held easy, but in rest; and the legs should hang straight down from the knee, and must not be permitted to work along the sides of the horse. 


\section{CHAPTER VII.}

THE GALLOP.

IN the gallop, which is a succession of leaps, the rider will lean slightly back, so that the buttocks will be carried well under him, and hold the body without stiffness.

The positions of the body must, however, always conform to the action of the horse, and to the direction in which he goes; and practice must show what, and how great, these changes should be.

In the gallop the horse must be true, to insure his balance and safe footing. To 
be true in the gallop the fore and corresponding hind-leg will be in the lead of that side to which the horse is turning or moving.

For instance, if it is the intention to turn or to move the horse at a gallop to the right he must have the head and croup bent to the right, and must take the long strides of the gait with the fore and hind leg of that side. This will preserve his center of gravity, and in case of a mistake he has his legs in under him to help him to a recovery.

If the horse is galloping in a straight line it makes no difference with which of his fore-legs he takes the long stride or lead, provided the hind-leg of that side corresponds.

If a horse takes the long strides with 
the right fore-leg and the left hind-leg he is disunited, and has not got his powers well in control. If in turning to the left he is leading with the right legs, he can with difficulty retain the center of gravity, and is apt to fall at the slightest blunder.

We say that a horse leads on that side when he makes the long strides with the legs of one or other side. But the fact is, the fore-leg of the other side leaves the ground before the fore-leg which makes the long stride does, and the same thing is true of the hind-legs. But the legs on the side to which he has been bent pass the others in their longer stride, and the horse is said to lead with them.

To put the horse into the gallop, leading with the off-leg, let the rider collect him, then lightening the forehand, and 
particularly the right shoulder, with a play of the direct rein, let him press in the left heel. In consequence of these movements the horse will take the gallop with the legs on the right side making the larger strides ; for the right shoulder is free to extend itself in answer to the propulsion of the forces from the croup, and the hindquarters being bent around to the right, the hind-leg on that side must follow with a similar step. The croup of the horse, bending to the right at the application of the opposite spur, will make the longer stride with the hind-leg that is so advanced, and such a movement is required to preserve the center of gravity under the conditions.

The horse having been put into the gallop, he will be aligned upon the path he 
follows by means of the hand and legs. The trained horse under the skilled rider will take the gallop upon the right or upon the left leg without bending perceptibly; for so perfect will be the equilibrium and the control, that the measured use of the aids will inaugurate a movement that will - not require correction. 


\title{
CHAPTER VIII.
}

\author{
LEAPING.
}

The pupil should first practice the standing leap, and upon a well-trained horse. The horse standing at the bar will be induced to rise by transferring the forces of the forehand back, and by the pressure of the legs will be made to spring forward.

As the horse rises the rider will bend slightly forward, giving the horse the reins. When the horse leaves the ground the rider should lean back, so that he may [72] 
preserve his center of gravity, and by bringing his buttocks well in under him receive the shock in the strongest possible seat.

As the hind-legs of the horse reach the ground the rider will resume his erect position. Any bearing upon the stirrups will disturb the seat, and may cause the rider to fall.

There must be no attempt on the part of the rider to lift the horse, and when the hand has played its part of conveying back the forces of the fore-quarters it must ease the tension of the reins until the fore-feet of the horse touch the ground, when he will feel the mouth to give the horse such support as he may need to recover the equilibrium.

In taking the flying leap the seat will 
be nearly the same as that for the gallop; the rider will not lean forward as in the standing leap, for the action of the horse will not require it, and if he swerves or refuses the rider should be sitting well back to avoid a fall.

As the horse makes the exertion for the jump the rider will bring his breech well under, lean back as far as the effort the horse is about to make shall demand, and resume the position for the gallop when the horse alights, at the same moment collecting him for the same speed with which he approached the leap, but taking care not to check him or harass his movements.

When the horse takes the flying leap he must have the fullest liber ty of his head; the bit being used only to direct him to 
the obstacle, and its tension released before the horse rises in the leap.

The legs will be carried in close to the sides of the horse to support him, but he should be neither spurred nor whipped at the jump, as it distracts his attention at a critical moment.

If he requires it the horse should be roused before he comes upon the ground where he is to decide upon his place for taking off, and from that time he should be left to himself until he receives the support of the bridle as his fore-feet touch the ground. The trick of throwing up one arm, or of giving a cry of encouragement to the horse as he rises, may work mischief by causing him to swerve, but it is then too late to offer him aid in gathering for the leap. 
The horse should not be ridden to a high leap at a speed that extends him too much. He should not be so flurried as he approaches a wide leap that he cannot use his instincts for safety. If a horse jumps in a slovenly manner he should be remanded to the school. 


\section{CHAPTER IX.}

VICES, TRICKS, AND FAULTS.

THE severity with which a horse has been punished for a fault is, usually, the measure of the violence with which he will repeat it. It is this violence that makes the horse so dangerous in his rebellion, for until he loses his reason he will take care not to injure himself, and so in a measure protects his rider.

Few young horses are dangerous in their resistances until they have met with cruel treatment. It is seldom that a colt 
in breaking will bolt with his rider; it is usually the old offender who is guilty of this most dangerous of vices.

Although nearly every young horse will rear at the pressure of the bit, he will seldom rise to a dangerous height, and he soon ceases to offend in that way. A horse must be corrected and put right, but it is never necessary to resort to severe punishments.

Fortunately the horse is an animal of one idea, and when he has determined upon his line of opposition he is easily circumvented and humbled. If he refuses to turn to the right he will be so intent upon opposing the right rein that he may be turned around to the left until he is confused, when he will very gladly go in any direction. If he declines to go forward he 
is not prepared to resist a demand for a backward movement, and he will soon tire of that unusual mode and start forward at the first hint from his rider.

But a horse properly broken and trained will not be guilty of such contumacy, and will not be apt to show the vices of which I am about to speak, but for which the rider must be prepared.

If a horse bolts the rider should not fatigue himself by taking a steady drag upon the mouth. Leaning back, with the breech well under him, and bearing no weight in the stirrups, the rider should take a succession of pulls upon the bit, one following the other sufficiently near to obtain cumulative effect. When the horse appears to yield to the bit, advantage should be taken of the moment, to 
prevent his again extending himself, by increased exertions upon the part of the rider, whose power should be reserved as far as possible to seize this opportunity.

I know of no way to prevent a horse bolting; by keeping his head up with the snaffle-rein the rider will have greater command of the horse, but the use of severe bits will not deter a confirmed bolter from indulging his vicious propensity.

If a horse rears the reins should be loosened, and if the rider require support he should seize the mane, without, however, letting the reins drop from his hands. The spurs should not be applied while the horse is rising, but as he comes down the legs of the rider should be 
closed to induce the horse to go forward.

If the horse refuses to go forward, the rider will find the side of the mouth with which the horse is not prepared to resist, by drawing the reins from right to left, and holding the rein of that side low, he will pull the horse around, aiding the hand by the application of the spur on that side.

If, when the horse rears, he sinks upon his hind-quarters, the rider should endeavor to leave the horse by seizing the mane and throwing himself aside, and although he may not be able to clear himself of the horse, he will at least avoid coming down under the saddle.

If a horse is shy at passing an object he can generally be made to proceed by 6. 
turning his head away, and passing him along with the leg opposite to the object, as in traversing.

If he is a young horse, and has not been maltreated, he will usually face that which has caused his alarm if he is allowed to take as much room as the way offers.

The rider should avoid, as much as is possible, taking notice of the horse's fright, as any nervousness on the part of the rider will confirm the horse in the opinion that there is danger.

If a horse takes alarm on the road at things with which he is familiar, it is either through defective eye-sight, or because he has found out that he can take liberties with his rider.

A man of discretion will know when 
a horse should be whipped up to an object of which there is a pretense of fear, but the horse must never be struck after he has passed on.

I do not like a horse that has low action, for he must trip, and he is likely, sooner or later, to come down. A horse stumbles when, through weakness, weariness, or stiffness from age and work, he is not able to recover himself from a trip. He usually bears the evidence of his accident on his knees.

A horse that stumbles from weakness is not fit for saddle use. If the rider is unfortunate enough to find himself mounted upon a horse that gives indications of being insecure upon his feet, he should demand free and lively action, with rein and legs. The horse should 
84 VICES, TRICKS AND FAULTS.

not be allowed to become indolent, nor be permitted to hang upon the bit.

On descending a hill the horse must have liberty of action, for if he steps too short he is liable to come down; and a horse that is checked has not sufficient freedom for his safety.

It is after a long day's work that a weary horse may for the first time stumble, and it is a mistaken idea of kindness that induces the rider to let a horse take his head upon such an occasion. The horse misses the encouragement of the rein and the support of the leg, and is invited to fall. Besides, it is much more fatiguing for him to bear his burden, deprived of his usual aids, and in drooping spirits.

Finally, in case of a fall, either of a 
VICES, TRICKS AND FAULTS. $\quad 85$

stumbling horse, or under any other circumstances, the rider should hold on to the rein until he is assured that his feet are free of the stirrups. 

P A R T I I.

I $\mathrm{N}$ T H E $\mathrm{S}$ C H O O L. 



\section{CHAPTER I.'}

THE EQUILIBRIUM.

THE rider should understand that it is not by the bridle alone that he should govern the horse; for the bit acts directly only on the forehand of the animal, while the croup or hind quarters will, without some other aid, be left ungoverned, to follow the forehand in a disconnected and unregulated manner.

It is necessary, therefore, that the rider should obtain the same control over the hind quarters of the horse as the bit gives 
him over the forehand. To accomplish this we must accustom the horse to bear the application of the spur and to answer its demands.

The horse is propelled by the hind quarters and is guided by the forehand, and it is to collect and govern the forces of these parts that we first turn our attention.

If the horse be not collected and his forces be not balanced, he will move in an awkward and uneven manner; the forehand dragging the croup, or the croup forcing itself upon the forehand.

I may illustrate this subject of the equilibrium of the forces of the two extremities by describing the action of two men bearing a sedan-chair. If the movements of the two bearers are not similar 
and in unison the motion is awkward and uneven, and both are hampered and constrained by the want of uniformity of speed and stride. If the man in front walks more rapidly than his fellow he not only carries his own share of the burden but has the drag of his slower bearer, while if the man in the rear moves at the more rapid pace he not only takes upon himself additional labor but even disturbs and harasses the man before him.

But when both men move with equal step and equal speed the weight is evenly and properly distributed, and the movement is easy and regular.

In a like manner the two extremities of the horse must be brought to work together to insure a uniform, light and regular movement; and this can only be 
done by acquiring and exercising control over both the forehand and the croup.

The reader may be tempted to think that nature ought to be expected to look out for these things, and that an animal evolved with four legs ought to use four legs together better than two animals each evolved with two legs can use their four legs together. Undoubtedly he can, but no untrained creature is fit for artificial uses, any more than the raw recruit has the strong and effective carriage of the trained soldier.

No matter how well balanced a horse may be naturally, the condition of affairs is changed when we put upon his back the weight of a man and his trappings; and the animal must be taught to conform his carriage to the new disposition of weights and forces. 
But if the horse be naturally ill-balanced, with so much more care must he be trained.

If the horse be deficient in the forehand, and high and strong in the croup, we must strengthen and aid the forces of the former, or the animal will be heavy in front from the preponderance of the forces of the hind quarters, and will struggle against the hand. It is usually the horse of this make that in unskillful hands becomes a bolter and a runaway.

If the horse be strong and well-made in the forehand, but weak and deficient in the croup, we must bring up and strengthen the latter, so that its forces may meet and balance the forces of the forehand.

Most of the resistances and refusals of young horses in tiaining are due to the 
fact that the animal is not in a position to obey the demands of his trainer, and a horse will seldom refuse compliance to any demand that he understands, if he be placed in the position that renders his obedience easy.

That this position is that of equilibrium must be apparent, for his forces are there collected and balanced, and he is able to make any movement without further preparation.

To obtain this equilibrium the horse must be light in hand, and the croup must readily answer to the pressure of the legs. How to teach the horse to yield to the bit will be explained in the next chapter; and, although the method of suppling the croup is given at length in another place, I may say here that the horse may be taught to answer to the pressure of the legs 
by tapping him upon the croup with the whip held behind the rider's back, while both heels are pressed into the horse's flanks. When the horse will answer to the pressure of the heels by bringing his hind-legs in under him, the taps of the whip should be abandoned and the heels only should be used.

The approximate equilibrium must be constant, for the moment that it is lost altogether the horse becomes heavy, and one extremity or the other must drag in action. This not only applies to the forward or backward movements upon direct lines, but to all changes of direction and traverses to either side. Of course, in every movement the equilibrium is more or less disturbed; but the better it is kept, the lighter and the more graceful will be the action. 
This will be experienced by anybody riding a horse unaccustomed to the saddle, and riding him again after the animal has had some experience, not to say training. The motion of the green horse is nearly always dull, heavy, and uneven when first mounted, and even the good rider finds but little pleasure or comfort in the awkward and disconnected movements of the unbalanced horse, which carries an unaccustomed burden and is harassed by the restraints of the bit. After a time, if he rides the same horse frequently, he will find things going more smoothly, and the young rider will be apt to suppose that it is because he is "getting used to the horse." That is, in a measure, true, but it is much more because the horse is getting used to move with the new burden on 
his back. Now the improvement in equilibrium which thus comes from even unskillful use, may be greatly increased by systematic training.

Union and balance must be kept, as far as is consistent with the rate of speed that the rider demands, when the forces of one extremity are advancing, and those of the other are pressing forward to find the point of balance. If the speed is to be increased, the legs of the rider will act upon the croup and the hand will give more freedom to the forehand. If it be desired to moderate the speed, the forces of the forehand will be brought back by the hand; and when they are brought to a point where they balance the forces of the croup, a halt is brought about.

First, then, we will consider the training of the forehand, and then that of the croup. 


\section{CHAPTER II.}

SUPPLING THE FOREHAND.

THE horse will first be ridden in a plain snaffle bridle, the trainer holding a rein in each hand, at such a height as he finds gives the horse the greatest freedom of action. He will induce the horse to move forward by some encouraging sound, or by a gentle pressure of the unarmed heels.

Upon coming to a turn the inside rein will be drawn to bend the head of the horse in the new direction, and the outside rein will support and steady the movement, while the outside heel may, by a slight [98] 
pressure, bring up the croup of the horse. When the horse will turn readily going in one way about the school, he will be ridden in a similar manner to the other hand.

He will then be ridden in the figure of eight, taking the whole length and breadth of the manége, or training-ground, in the movement, and the rider will use great care in shifting the aids at the extremities of the diagonal lines.

During these lessons, the duration of which will depend upon the aptitude of the horse in acquiring the habit of obeying the bit, he will be permitted to walk in the manner that pleases him, or rather, in the only way he knows, usually a loose shambling gait, with very extended strides of the hind-legs.

He will then be taught to carry himself 
in a more collected manner, and to step in a regularly-cadenced and even walk, and then in a slow, measured trot, likewise cadenced.

On the outside path of the manége he will be put into the walk, and as a hind-leg is raised to step forward the rider will press in his heel on that side, and immediately after meet it with the corresponding rein, and he will do the same thing at each step of the other hind-leg. This action of the aids will shorten and equalize the strides of the horse, and by bringing back the forces of the forehand to meet the advancing forces of the croup, render the horse collected and light in movement.

The speed must be kept regulated, and the horse must not be permitted to hasten or to decrease his walk at the unaccustomed 
application of the aids. This regularity may be aided by the encouragement or the soothing of the animal by the rider's voice, as the horse hangs back or hastens forward.

The horse should be brought to a halt by the rider pressing in his heels, to carry the hind-legs under the animal, and the hand quickly acting upon the mouth to check the forward motion. The hand to follow the pressure of the heels in time to prevent a second step by the hindlegs, but so gently as not to harass the horse.

In the same way the horse will be made to take and keep a slow, measured trot, the action of the animal, not his speed, increased by means of the aids. But these lessons must not be carried too far, as it 
is not now the intention to develop the trot into the passage, but simply to give the horse light, even, and regular strides; and when this has been acquired the horse will be habitually ridden with an equal pressure on both sides of the mouth when the bit is in action, though never with a constant pull upon the reins.

After the horse has acquired the walk and the trot as described, he should be ridden in the double-reined bridle, the curb-bit being carefully fitted, but sufficiently severe to make him discover that it is for his own comfort that he yields his head and jaw at its pressure. I have found that bits with branches from four and a half to five inches in length, from the center of the mouth-piece, answer the purpose; and as my horses never rear or fight against the 
hand, I think that bits of this description may be used by those riders who do not trust to the reins for support.

When the rider first mounts the horse bitted with curb and snaffle, he will draw the curb-reins up until he has a gentle feeling of the horse's mouth. Then with the direct rein, the horse being at a halt, he will make light vibratory motions to induce the horse to give his jaw upon one side, and afterwards he will, in the same manner, make the horse yield his jaw to the other rein.

Then, with both reins at equal length, he will play with the bit until the horse yields his jaw and carries his head perpendicularly, giving the hand the moment the horse yields, so that the animal may understand that he has done that which 
was demanded, and that he is rewarded for obedience.

These results cannot be accomplished at once, and in case of resistance the trainer should, after a few trials, cease his efforts and turn his attention to some other part of the education of the horse. But when the horse has refused obedience through ignorance or stubbornness, while he must not be punished, he should not be led by any act of kindness to think that his refusal has met with the approbation of his rider.

I wish to say here, at the outset of these instructions in training, that I am opposed to severe punishments under any circumstances. I have seen severity tried in many cases, and for years I was under the belief that positive disobedience should 
meet with quick and sharp penalties, but I have never seen good results follow such treatment; while, on the other hand, I have never known patient kindness fail to conquer the most stubborn animals.

Besides other advantages of the course I recommend, it reduces the dangers of training to a minimum; and the only injury I have received in schooling many horses, a very slight one, I am happy to say, was the result of an angry blow given to a young horse who tried my patience beyond the bounds of my philosophy. This lesson was not lost upon me, and I have found the same horse perfectly docile when treated with firmness and kindness.

The spur and whip must be used, but the horse should not look upon them as instruments of punishment, and it is sur- 
prising how quickly a young and spirited horse will answer to the application of these aids without flinching or resentment. I find that a harsh word will answer every purpose of correction, and all horses understand and fear the angry tones of a man's voice, as they are soothed by his kind words.

We will now return to give the horse his first walking lesson in the doublebridle.

Taking the curb-reins in the left hand, divided by the little finger and grasped by the thumb, while the snaffle-reins, divided by its width, are held above them in the right hand, the rider will move the horse upon the outside path of the riding-school to go around to the right.

When the horse, at a walk, arrives 
upon the path, the left hand will, by a series of gentle vibrations of the curbreins, giving an equal bearing on both sides of the mouth, induce the horse to yield his jaw and to carry his face perpendicular to the plane of movement.

The height of the head, which should depend upon the conformation of the horse, must be regulated by the snafflereins, as the curb-bit has a tendency to make the horse carry his head too low.

But the two bits must not act simultaneously; when the right hand is to play with the snaffle, the left hand must ease the tension on the curb-bit, and this rule for the independent use of the bits must be observed under all circumstances.

Should the horse hang back, the hand will yield, and the closed heels will press 
him forward, then the rider will renew the action of the bit.

When the corner of the school is reached, the tension of the curb-reins will for a moment cease, and the horse will be turned in the new direction by the snafflebit held in the right hand; but before the change is completed, the snaffle-reins will be eased, and the outside curb-rein will be carried against the neck of the horse, to teach him to bend at the application of the curb.

At each corner of the riding-school these applications of the aids will be practiced, and upon the straight lines the curbbit will call upon the horse to yield his jaw and head, the tension upon that bit ceasing the moment the horse obeys the demand. 
After a few turns about the school to the right, the reins will be changed, the left hand holding those of the snaffle above the curb-reins now in the right hand, and the horse will be walked the reversed way.

In the straight lines the horse will be kept collected between the hand and legs, and as he learns to yield to the bit and answer to the heel, he will become light.

When the horse turns readily at the corners in answer to the snaffle followed by the curb, he should be turned by the use of the curb alone, the outside rein being pressed against the ncck and the corresponding heel bringing up the croup. After he makes the turns at the corners at the pressure of the curb-rein, he should be ridden in the figure of eight, taking the 
full length and breadth of the school, and then gradually taught to go in circles to the right and left, the equilibrium being always required.

In the same way, using precisely the same means, the horse should be taught to trot and gallop in measured speed in the equilibrium - the head carried in a perpendicular position, the jaw yielding to every touch of the curb-rein, and the action even and regular.

Should the horse lose his equilibrium in the trot or in the gallop, and become heavy in hand, he should be brought to a halt, and after the equilibrium is re-established he should be again put in the action, so that he may know his fault and correct the habit.

As a rule the horse should after every 
mistake be brought back to the first principles of the movement he is attempting.

The reason for demanding the yielding of the jaw is obvious, for the horse then is incapable of resistance against the bit. The position of the head also is an acknowledgment of subjugation; for while the horse may freely hold it at any height to insure ease and grace of carriage, he cannot so well oppose the demands of the bit as he could were his head held stiffly out or braced against his chest.

In this stage of his education it is excellent practice to bring the horse to a halt and to carry his head first to one side and then to the other, until he looks to the rear, by the gentle play of the direct rein; and requiring him to yield the jaw while the head is turned to the rear. After 
bending to either side, the neck should be straightened and the jaw made to yield before the head is bent to the other side.

The different action of the two bits must be constantly borne in mind. The snaffle-bit will be used, in short pulls upward, to make him carry himself light in front, if the horse be naturally heavy in that part; while the curb-bit will be employed to overcome the active resistance of the horse, and to direct and rule the forces of the forehand after the snaffle has accomplished its work. But the two bits must never be used together, no matter how rapidly the effects of one must follow those of the other. 


\section{CHAPTER III.}

SUPPLING THE CROUP.

To bring the horse under the control of the rider it is necessary that the forces of the croup should answer to the application of the legs as readily as the forehand yields to the demands of the bit.

The trainer, standing at the near shoulder of the horse, will, in his left hand, grasp the reins of the curb close to the branches of the bit, and, by drawing them towards the animal's chest in gentle vibrations, induce him to yield the jaw and carry his head in the perpendicular posi- 
tion; at the same time he will tap the horse upon the rump with the whip, held in the right hand, until the hind-legs are carried under the body, and the horse is brought into equilibrium.

The taps of the whip will then be transferred to the left flank until the horse carries his croup over one step to the right. The forehand will be kept in place by the reins, and although the forelegs have not been raised from the ground, the off fore-foot will, in the new position, be slightly in rear of the line it should occupy. A tap of the whip upon the under side of the right fore-arm will bring that leg up to its place, and the horse will be straight in the new position.

In this way the horse will be taught that, although the forehand must not 
move away from its ground, the inside fore-leg must be raised and advanced to accommodate itself to the new position that the mass has taken.

The horse will be made to carry the croup, step by step, around the forehand, the near fore-leg acting as a pivot, and the off fore-leg moving enough only to bring him straight after each step made by the croup. He must not take more than one step at a time, and he should be permitted to move only when it is required of him.

In a similar manner, standing at the off shoulder, the trainer will make the horse pass the croup about the forehand in the opposite direction, the off fore-leg acting as the pivot.

These exercises will be employed 
between other early lessons, until the horse will pass to the right or to the left without removing the pivot-leg, and without losing the equilibrium.

The power of the whip will now be transferred to the legs of the rider, in the following manner :

The mounted trainer will bring the horse into equilibrium by hand and legs. He will then pass the whip, held in his right hand, behind his back, and tap the horse upon the near flank, pressing in the left heel at the same time, until the croup passes one step to the right. The right leg of the rider will be held close to the flank to prevent the horse drawing back or making more than one step, while a play of the right curb-rein will overcome the resistance of the right shoulder of the 
horse, and, lightening that side, induce him to bring up his right fore-foot to the line that will put him straight in the new position.

Step by step the circle of the croup about the near fore-leg will be completed, care being taken to put the horse straight after each change of position, and the opposition of the forehand overcome by the play of the direct rein of the side to which the horse moves.

By similar means the horse will be made to circle the croup to the left about the off fore-leg as a pivot.

When the horse will make the reversed pirouettes in the manner above described with lightness and precision, he will be made to pass, to the right and to the left, about the outside pivot-leg with- 
out halting at each step; the proper forefoot being brought up with each movement of the croup to maintain the straight position.

The next practice will be to make the horse move the croup one step to the right, then one step back to the left, one step again to the right, and so on, until he obeys the pressure of the legs without hesitation.

In all movements of the croup about the forehand the head of the horse should be bent towards the advancing croup, and the forehand should be kept light by the play of the direct rein.

These lessons will render the horse ready and quick, and he will soon obey the pressure of the leg without waiting for the prick of the spur, the more severe 
form of the aid being held in reserve to be used only when required.

Having obtained control of the forces of the forehand and of the croup, we have the horse under command, and we may perform any movement by the proper employment of our powers.

The pressure of the heels will not increase the speed beyond the liberty allowed by the hand, and the horse should be accustomed, by the restraint of the hand and the pressure of the legs, to modcrate his speed, or even come to a halt, in a collected form.

In bringing the horse to a halt, the heel pressure will precede the action of the hand. In reciucing the speed, circumstances wiil dictate how much, and when, the aids will act. This collected state 
gives the horse security in his movements, as he is always ready to recover from a mistake, and it is necessary for the maintenance of equilibrium. 


\title{
CHAPTER IV.
}

\author{
TO BACK.
}

All horses should be taught to move backward with ease and lightness; not only that the animal shall be prepared to go in every direction, but also that he may the more readily learn to collect himself and be quick and ready in his movements.

Backing is a movement not natural to the horse, and he must be made to abandon all repugnance to the unusual action, and be taught how best to perform it.

If the horse be made to back by means 
of the bit only, the forces of the forehand will bear down and cramp the croup, and if any movement to the rear takes place it must be with difficulty and awkwardness.

It is evident, therefore, that, if the movement is to be made with ease and grace, the forces of the croup must be brought up to a point nearly in balance with those of the forehand, but yielding to the latter sufficiently to permit the retrogression at the desired speed.

It is not possible for the horse to back with rapidity and retain his lightness, and the school-terms of the "gallop backward " and the "trot backward " mean only that the motions of those paces are observed while the horse moves slowly to the rear. 
To teach the horse how to back, he should be brought, saddled and bridled, upon the training ground. The trainer will then, by means of the left hand acting upon the reins beneath the chin, and the taps of the whip upon the croup, bring him into equilibrium. Then, by continuing the taps of the whip upon his croup, the horse will be made to raise one of his hind-legs, but before the mass gets a forward impulse the hand will carry the horse back one step, and before he loses his lightness he will be made to advance a few steps.

In the next lesson he may be made to take two or three steps to the rear, and to advance several steps before the equilibrium is destroyed.

By short progressive lessons of a few 
minutes each day, he will be practiced until he will carry himself a number of paces to the rear without losing the equilibrium, which should be retained by the hand and whip acting upon the forehand and the croup, as either requires the stimulant of an aid.

Care must be taken to keep the horse perfectly straight at all times; and to assist the trainer in this it is well to have the horse along the side of a wall.

After the horse has been taught by the trainer on foot to move backward with lightress, the man should begin the mounted lessons. The rider will bring the horse into equilibrium at the halt; then pressing in his heels until the horse raises one of his hind-feet, as if to advance, the rider will carry back the balanced mass 
one step by a light pressure upon the bit, and immediately make the horse advance by yielding the hand and closing in the heels.

Each day the horse will be made to take an additional step, or more if he still retain his lightness, until in time he is able to go any distance to the rear without becoming heavy.

If the croup yields too much to the coming forehand, the heel of the rider will support the croup upon the side of the lifted hind-leg, and the pressure of the bit should only be felt as each step is made, and then only sufficiently to bring about the movement. Of course, the horse must be kept perfectly straight by the ready pressure of the rider's heels.

The horse should not be permitted 
to come to a halt after backing until he has made a few forward steps without a break in action. 


\section{CHAPTER V.}

THE PASSAGE.

The passage is a kind of trot, of very brilliant action, in the highest possible equilibrium. It is usually employed in traversing, as the position in which the horse is found at each stride is favorable to his balance in moving to the right or to the left.

In the passage the weight of the horse, at each cadence of the gait, is borne by a fore-leg and its diagonally opposed hind-leg, and from the spring given at each step he is for the moment in the 
air. The effect of this action is striking and graceful.

The passage is produced by putting the horse into a slow trot and restraining the forward movement, while great exertion is demanded by the spurs. The opposite spur is applied as the horse raises each fore-leg in movement, and the hand meets and opposes the spur as the hind-leg of each side is thus brought into action. That is, the spur and the rein of the same side serve to produce the action, shorten the stride and restrain the speed.

If the horse is about to lead off with the right fore-leg, the rider will apply the left spur to increase the croup action and to support the raised fore-leg, and will immediately after draw the left rein 
to check the forward impulse, and in that way further increase the action and produce the momentary halt that adds so greatly to the effect of this trot.

The speed must be very moderate and regular, at each stride the momentary rest must be marked, and the equilibrium must be maintained.

The exercises with hand and heels, recommended in Chapter II. for giving the horse a steady, regular step, are admirably adapted for preparing the animal for his lessons in the passage. Indeed, the aids are the same in both cases; and in the passage the diagonal action, if I may use the term, is produced by the accentuated use of the spur forcing the croup while the hand restrains the forehand; and another effect of the combined 
aids is the height and brilliancy of the step.

After the horse has been perfected in the passage, the intermittent pulls upon either side of the mouth may cease, and the hand will take an even bearing upon the reins whenever it is necessary to feel the mouth, and the slightest pressure of the rider's leg only will be required as the horse leads with the opposite fore-leg.

But the application of the rider's legs should not cease while the horse is to be retained in the action of the passage; and it should be a rule that, except in the walk, the trot, and the gallop, in direct lines, the horse should never be allowed to maintain a school movement after the indication of the aid ceases; 
otherwise he may volunteer an undesired performance.

After circling, traversing, the changes of leg in the gallop, or the movements in place and to the rear, the horse will be put into direct lines in the same action in which these are performed before he is brought to a halt. This rule does not apply to the horse while he is learning the rudiments of the movements, because it is often necessary to bring him to a halt to correct an error, but after he can perform the various airs he should be taught to observe it. 


\title{
CHAPTER VI.
}

\author{
THE PIAFFER。
}

THE piaffer is simply the passage without advancing; and the horse will be brought to perform it by giving him the action of the passage and then preventing him from gaining ground by carrying back the forces of the forehand with the bit.

At first the rein and spur will act at each step, as in the passage, but after the horse has acquired the action it will only be necessary to keep him light in front and to use a gentle pressure of the rider's leg [132] 
as the animal raises the opposite fore-leg and its diagonally disposed hind-leg to sustain the movement,

The piaffer is useful in rendering the horse light, and in putting him in a position from which he can make any movement with great celerity and precision, as he will be ready to advance, to retreat, or to traverse to either hand without further preparation.

This is a movement difficult to control, and the equilibrium is of the highest importance. It should not be undertaken until the horse is quite perfect in the passage, and has been taught to back with ease and lightness.

The lessons in the piaffer should be given every day, but for only a few minutes, as the action is very fatiguing and 
harassing to the horse, and he is apt to become careless and heavy.

The advance in the passage should be gradually decreased, and when the horse has made a step or two in place, or in the piaffer, he should be permitted to again advance in the passage and be rewarded by a kind word.

In a short time, increasing the number of steps in the piaffer at each lesson, the horse will perform the movement without difficulty, and can be made to begin the action from the halt.

But if the first lessons are given from the halt, the horse must offer more or less resistance, and will frequently become violent in his opposition.

The rider must endeavor to obtain a regular and even step, each leg having the 
same height of action, and the whole movement being made with that springy motion that is proof of a high state of equilibrium. 


\section{CHAPTER VII.}

TO BACK AT THE PIAFFER.

THE means for producing a backward movement in the piaffer should be apparent to all who have read the preceding pages, but great tact and discretion are required, and perfect concord must exist between horse and rider.

When two legs of the horse are raised in one of the steps of the piaffer, the hand will carry the balanced mass to the rear, and they will come to the ground a few inches to the rear of the position they would take in the piaffer in place. 
The increased tension upon the reins should cease the moment the impulse to the rear has been given, to be felt in the same way at the next step of the other pair of legs. The spurs will keep up the action of the piaffer, and prevent too precipitate a retreat.

When it is desired to go forward the hand will yield at some cadence of the movement, and the increased pressure of the heels will carry forward the raised legs of the balanced horse.

In this, as in all other movements, the rider should sit quietly upon his horse, so carrying his hands and legs that his motions in applying the aids shall be almost imperceptible. It detracts greatly from the appearance of a horseman to be seen making violent efforts with hands and heels, 
I38 TO BACK AT THE PIAFFER.

and the shifting of his weight under such circumstances disturbs and hampers the horse. 


\section{CHAPTER VIII.}

CHANGES IN THE GALLOP.

THE gallop is a succession of leaps, in which the legs of one side leave the ground after, but pass beyond, the legs of the other side; and the horse is said to lead with the side making the more extended strides.

If the horse take the long strides with one side, and turns to the other in changing direction, he is false in his gallop. If he take the long strides with a fore-leg and the diagonally opposed hind-leg he is 
disconnected. That is, to be true and connected in the gallop the horse must always lead with the side towards which he is turning or traversing, and the legs of the same side must correspond in action.

In the gallop the horse rises more upon the side with which heleads, and the croup is bent to that side to enable his hind-leg to make a stride corresponding with that of the leading fore-leg; and here we have the key for demanding its performance.

If we wish, therefore, to make the horse gallop leading with the right side, we shall lighten that side by a play of the direct-rein, and bend the croup by an application of the left spur. When the horse strikes off, the hand and legs will align him upon the path he is to follow, 
and collect him for the desired speed. To this end the leg opposite to the spur must be carried closely to the flank, to be ready to give support, and to prevent too much yielding to the rowels.

This method must not be confounded with that prescribed by military writers, for although the instructions appear to have great similarity, the effects are very different. In military riding, the rule for making the horse gallop with a snafflebridle is to raise the opposite rein, lower the direct-rein, and apply the opposite spur.

The theory I advance would require the reverse of this, so far as regards the reins. The "double-feeling" of the direct curb-rein in the cavalry schools is not the play or vibration that I advise to lighten 
the side with which the long strides are to be taken; for the soldier by the "doublefeeling " of the direct-rein bends the horse's head to that side, and with the opposite spur brings about the croup, and the horse must take the gallop with the side so collected. But while the desired action has been brought about, the horse cannot have that grace and freedom of action that follows the method of lightening the side that is to lead.

All authorities, other than the one I have just referred to, follow the old rule of "the opposite rein and opposite spur," until the horse has been taught to gallop with either side, when some other and more proper method is substituted. But there can be no good reason for adopting a false method by which to teach a move- 
ment if a horse can be taught by the proper method from the beginning.

If the horse is lightened in front by a play of the bit, he may be lightened more upon one side than upon the other by the increased action of the bit upon that side ; and by this method the horse may be trained to gallop by the use of the same means that shall be used to make him perform the movement after he has been trained. I have employed the rule founded upon this theory with complete success, not only in teaching the gallop, but in schooling for all those movements requiring the lightening of one side of the horse, as in the pirouettes and traversing. As the horse can best maintain his balance and keep his footing when he is true and connected in his gallop, it is of 


\section{4}

CHANGES IN THE GALLOP.

the first importance that the rider should be able to demand the changes of leg while in action; but this requires long schooling and great tact.

The horse must first be taught to gallop leading with either side, at the will of the rider, in a regularly-cadenced gait, in direct lines and in circles. While galloping in a direct line he will be brought to a halt, and then made to lead off in the fallop with the opposite side.

When he will perform this change from the halt with clearness and precision, he will be slowly galloped in a circle and, without the halt, changed to a circle in the opposite direction, the hand acting upon the forehand as it rises, and the spur of the opposite side pressing in as soon as the forehand bends to the bit. As 
the hand acts the body of the rider will be carried back, to be brought forward again as the spur is applied.

This use of the aids and disposition of the weights, as the horse is about to change the lead, will give the poise, at the moment the forehand is in the air, which enables the horse to take the new lead with smoothness and exactness.

The application of the aids must be made with celerity, but without unnecessary force or effort upon the part of the rider.

After the horse will make the changes neatly in turning from one circle to another, he will be made to change his lead in the direct line at any step without - halting.

But the horse must not be put forward IO 
146 CHANGES IN THE GALLOP.

until he perfectly performs each successive step in the lesson, and he must be brought back to the first principles of the movement whenever he becomes careless or awkward.

In demanding a lead of either side or a change in the lead, the horse will be bent no further than is absolutely necessary to obtain the movement, and in making the circles the body of the horse should conform to their circumferences.

It is hardly necessary to say that the highest equilibrium is essential to the performance of the changes. 


\section{CHAPTER IX.}

TO HALT IN THE GALLOP.

IN all the exercises for bringing the horse into equilibrium he has been learning to carry his hind-legs under him at the pressure of the rider's heels, and from his obedience to this indication we can readily get a finished halt from the gallop.

The horse will first be accustomed to come to a halt from the walk at the pressure of the rider's legs, closely followed by the raising of the bridle-hand. In the same way he will be brought to a halt from the trot. 
Then, being put into a measured gallop, the rider will bring him to a halt by pressing in the heels as the horse is beginning some cadence of the gait with his hind-legs, and raising the bridle-hand as the horse is beginning the succeeding cadence with the fore-legs.

The result of these applications of the aids will be that the horse will come to a finished halt at the completion of the second cadence of the gait. For at the pressure of the heels the horse will bring his hind-legs well under his body, and at the drawing of the reins he will arrest his action in the forehand, and he will come to the halt with his powers collected.

As the rider presses in his heels he should lean well back, so that his weight may aid in fixing the croup of the horse 
at the finished stride. The legs and hand of the rider must be used with promptness, but without violence, and the time must be well chosen.

After a few trials the rider will be able to seize the proper moment without being conscious of having noted the leaps of the horse; and in time he will bring his horse to a finished halt from the gallop with the same ease, and with as little thought of the steps to be followed, as he would use to turn to the right or to the left.

The halt in the gallop prepares the horse for the momentary rest that precedes the change of leg in the gallop, as the forehand rises for the new lead. 


\section{CHAPTER X.}

THE GALLOP IN PLACE.

THIS movement, and that which follows, may be performed only by a collected horse in the hands of a skillful rider. Under such circumstances there should be no difficulty in producing these brilliant effects.

When we first put the young horse into the gallop, we find it difficult to keep him at a measured rate of speed in a regularly-cadenced stride. But by the restraint of the hand, and the support and [150] 
encouragement of the spurs, we teach him to take and maintain the gallop at the desired speed. By the same means that we employ to regulate h:s speed we may prevent his progress, or even compel retrogression in the action of the gallop.

Before it is attempted to teach the horse the gallop in place he must be taught to gallop in direct lines in such a measured and collected manner that a slight change in the tension of the reins will not discompose his action.

The rider will then practice bringing him to a very slow gallop by the restraint of the hand, while the pressure of the heels will prevent him becoming heavy in the croup by demanding the action of that part. He will then be taught to begin the gallop at this very low rate of 
speed, and after a few strides be brought to a halt.

In time, he should be made to take several steps in place at starting, and then be allowed to go forward at the slow gallop, and be rewarded by a caress and a kind word for the few steps he has taken in place; for this movement is very trying to the temper of the horse, and he must, by short lessons and rewards, be encouraged in his efforts to obey the demands made upon him.

Each day the number of steps may be increased, but he should never be required to keep up this fatiguing and harassing action for any great length of time.

1 The forces of the forehand must not too greatly over-balance those of the croup, or the hind quarters will be fixed to 
the ground, and the movement will degenerate into a series of rearings. The spurs should keep up the forces of the croup, and the hind-feet should move at each leap.

The changes of leg in the gallop in place may be made in exactly the same manner as when the horse is advancing. 


\section{CHAPTER XI.}

TO BACK AT THE GALLOP.

To back the horse in the action of the gallop from the gallop in place, it is required that, as the forehand begins to sink in a cadence of the action, the forces should be carried back by the hand so that the fore-feet will touch the ground a few inches within the line they would have reached from the gallop in place, and the hand then giving way, the croup will be lightened and the hind-legs will be carried back far enough to find their proper 
position required to keep the horse collected at each finished step.

The movement of the croup to the rear will be measured by the spurs, and it must not be allowed to go so far as to make it impossible for the horse to rise at the succeeding cadence.

To move forward, and the horse should be made to advance before he comes to a rest, the hand will give liberty to the horse as he rises, and the spurs will act upon the croup, so that the horse will take a gallop in the direct line in a regular and even stride.

The gallop to the rear is a mere tour de force, to exhibit the skill of the rider and the training of the animal. The movement must be made very slowly, and exactly the right time must be taken to increase or yield the tension of the reins, or 
the balance of the mass will be destroyed and a mishap may ensue.

The gallop in place is in the true action of the gallop, and the horse is in a high state of equilibrium. But in the so-called gallop to the rear, while the horse must be in perfect equilibrium to begin the movement, the forces of the forehand must be carried back too far, and the changes in the points of balance are made too slowly to permit the horse to be always light.

Of course, the horse must be kept collected, and the action of the forehand and of the croup must be kept up in the best equilibrium possible, or the movement must come to an end. But a high state of equilibrium is not constant, though it may be regained when the horse moves forward in the gallop. 
I believe that no other writer has given a description of the action of the horse in the movement, and I know that the impression derived from the methods by which it is proposed to produce it is of an action very different from that I have described. I can only say that I have explained the movement as I have seen it performed by the horse, and I know of no other way in which the horse can move with lightness to the rear in any action that resembles the gallop. 


\section{CHAPTER XII.}

THE SPANISII TROT.

While I do not consider this movement to be within the scope of my work, for I do not see that it answers any useful purpose, I have undertaken to give several of the many methods by which it may be produced, because it is so greatly admired for the brilliancy and elegance of its action.

By one method the trainer will, stand-

- ing at either shoulder of the horse, bring him into equilibrium with a hand operating upon the jaw by the reins held beneath [158] 
the chin, and by the whip taps upon the rump. He will then walk the horse, thus collected, about the training-ground, and as the horse is about to raise each fore-leg, he will give it a tap with a stiff whip on the under part of the fore-arm, checking the advance at each step with the hand. In a short time the horse will raise and extend the fore-arm at the tap of the whip, making the exaggerated action of the Spanish march.

A rider will now mount the horse, and the power of the whip will be transferred to the spur, in the following manner:As the trainer, walking by the side of the horse, applies the whip, the rider will press in the oppositc spur and meet the impulse of the spur with a tension of the rein of the same side, to make the mo- 
mentary rest, and by checking that side lighten the other.

After a few lessons the horse will make the extended step with each fore-leg at the application of the spur and hand without the whip, provided that he is kept very light in front.

This march can readily be forced into a trot by increasing the speed and continuing the use of the aids. Two or three steps only at a time should at first be demanded at the trot, and the horse must be kept collected and light in hand; and, if necessary, the play of the rein may be marked, as he raises the hind-leg of that side.

After the horse has made a few steps in the Spanish trot he should be permitted to resume his natural action, and he should 
be rewarded for his exertions by hand and voice.

In time he should perform this movement at very slight indications from the aids, the thumb of the bridle-rein being turned at the wrist, towards the right shoulder or towards the horse's ears, as the right or left leg gives a light pressure to the flank.

We must not in the Spanish trot lighten the forehand by the direct rein, as in the gallop, because there must not be a cross pull in any trot, and we content ourselves by producing the momentary rest with the rein of the moving hind-leg, and by checking that side give freedom to the moving side of the forehand.

The Spanish trot is simply an exaggerated passage, with the strides forced forwards by increased application of the 
aids and by throwing back the forces of the forehand more than in the perfectlybalanced action of the passage, which takes place under the horse.

A second method for producing the Spanish step is very similar to the preceding, but is better adapted to nervous, excitable horses. In this second method the trainer will stand in front of the horse, facing him, and, walking backwards, will lead the horse in the best equilibrium he can procure under the circumstances. With a very slender whip he will touch the horse upon the front of the forearm as he raises each fore-leg in walking. This will have the effect of making the horse strike out, often to the peril of his trainer, with the fore-leg that has received the touch of the whip. 
The transfer of power to the spurs and the subsequent steps in training, will be exactly the same as described in the first method.

A distinguished school-rider, who gave me my first practical lessons in this movement, made it his custom to teach the horse, while at a halt, to give or extend his fore-leg at the whip taps applied below the knee, and as the horse raised the leg the trainer would seize and bear it up as high as he could. Afterwards he had a groom to walk backwards, facing the horse, and as the trainer, walking by the side of the moving horse, made him raise each fore-leg in turn, the groom caught it in his hands and borc it up for a moment, and then dropped it to treat the other foreleg in the same way. 
Even with the horse in a trot have I seen that groom dodging away from the excited animal, but seizing and lifting the fore-legs as they were thrust forward.

The result of this work was the most elevated action that I have ever seen, and the long pause between each step in the horse so trained was very effective. The power of the whip was transferred to the spurs by the usual method. I hope that my old instructor will not consider me indiscreet in explaining how he produced the wonderful action that was the envy of continental riders a score of years ago.

This is the least difficult to teach and to ride of all the school movements, and is of the least importance. 


\section{CHAPTER XIII.}

TRAVERSING IN THE PASSAGE.

WHEN the horse is directed to the right or to the left upon two parallel paths, by one of which moves the forehand slightly in advance of the croup which follows the other, he is said to traverse.

This is one of the most important of the movements practiced in military riding, and is useful to all horsemen in rendering their mounts obedient to the indications of the leg. It is usually performed at the passage, but the early lessons must be riven at the walk. 
If the horse be standing across the line upon which he is to move (that is, with his body making right-angles to that line), he will be made to carry his croup one step to the left, which will bring him into the proper position, with regard to the line of march, to traverse towards the right.

This position to the line of march is necessary to permit his legs to pass each other as he proceeds sideways.

The rider will lighten the forehand with the right rein, and induce a movement to the right by a pressure of the left heel, his right leg being held close to the flank to prevent the croup going over too far, and to keep the horse up to the line of march.

The horse must be kept at the same 
angle to the line of march, and his head must be bent in the direction he is following, and whenever the horse loses his. lightness he must be brought to a halt and collected.

In the same manner, right and left, aids being interchanged, he will be taught to traverse at a walk in the opposite direction.

When the horse will pass to the right and to the left upon straight lines without losing his lightness, he should be made to traverse in circles; care being taken to keep him, at each step, at the proper angle to the point of the circumference upon which he happens to be.

He will then be made to perform the traverse in the action of the passage.

The rider will put the horse into the 
action of the passage upon a direct line, and will, upon arriving at the point where he intends to begin traversing, keep the forchand at the same rate of speed, while he forces the croup to take, by extended strides, the proper position to the line of movement.

The action of the passage and the traversing will be kept up by accentuated pressures of the opposite spur, given as the horse raises the fore-leg of the side to which he moves; the inside leg of the rider will be held close to the flank to keep the croup in place and prevent the horse falling back from the line of march. The hand will lead and direct the forehand, and by the play of the direct rein will maintain the lightness of that part and carry the head of the horse in the direction 
he is following. It will be observed that the rein upon the same side with the acting spur is not used to bring about the temporary rest at each stride, as in the passage in direct lines, because this action of that rein would interfere with the traverse movement. The effect of the momentary rest is accomplished by the action of the outside spur giving one pair of legs greater action than the other two take in the alternate strides. The inside spur, while keeping up, if necessary, the horse to the line, is also used to prevent the croup passing over too far, but, of course, does not serve to heighten the action of the two legs it would act upon in the passage in direct lines; it rather checks them, though it is not intended that the inside spur should take any part 
I7O TRAVERSING IN THE PASSAGE.

in producing the action of the passage in the traverse.

At each step the weight of the horse is supported by a fore-leg and the hind-leg diagonally opposed, while the other two legs are carried beyond them in the direction of the movement. The manner in which the weight is thus borne permits the horse to keep his balance as he goes to the right or to the left, and avoids the danger of tripping.

The experiences of the rider in performing the traverse in circles at the walk, will teach him how to make the changes of direction at the passage.

But when it is desired to change from traversing to the right or left to the left or right, the progressive movement must cease, in order that the horse may take 
his position and balance for the new direction.

If the horse be traversing at the walk he should be brought to a halt, and the croup should be carried over to the proper side for the change; but if the horse be traversing at the passage he should be made to do a few steps in the piaffor and the croup may be carried over during its action. For it must be understood that, the forehand being in advance of the croup, the horse cannot traverse to the opposite side until these relative positions of forehand and croup are established for the new direction, and the balance effected anew. 


\section{CHAPTER XIV.}

TRAVERSING AT THE GALLOP.

Although the passage is the action in which traversing may best be performed, horses are brought to traverse at the gallop, both as a school movement and to prepare them for voltes and pirouettes.

Of course, the general principles for traversing are the same in all actions, and it is only necessary in the gallop to take the greatest precautions for preserving the balance of the horse in moving to either side, for his weight is not then so evenly supported as in the passage. 
The horse should be put into the gallop with the lead on the side to which he is to traverse; that is, if he be to traverse to the right he will be made to gallop leading with the right legs.

When he arrives at the point where the traversing is to begin, the croup will be carried over by the opposite spur, and the forehand will be bent and conducted by the direct rein. The inside spur must be kept close to guard the movement, and between hand and legs the horse must be kept at the proper angle to the line of progress.

As the croup moves into the position for traversing, the horse will probably be compelled to take a disconnected stride with his hind-legs, and this action will be corrected at the second stride in the new 
I74 TRAVERSING AT THE GALLOP.

movement by bringing up the croup. In like manner, when the horse is put into the direct line a false stride in the hind quarters must be looked for and corrected. In turning, the speed of the croup must be retarded so that the hind quarters will hold their relative position to the forehand at every point of the line; and likewise, in traversing in circles, care must be taken to keep the body of the horse at the proper angle to each point of the circumference.

This retarding of the speed of the croup will be governed by the graduated pressure of the outside spur, aided by the support, when necessary, of the inner spur.

If the horse be traversing to the right, and it be desired to pass in the op- 
posite direction, the movement to the right must end, and the horse must recover his balance and be put into position to the line of the new direction.

The action of the horse does not cease, for if he comes to a rest he loses his lightness; but the movement in the old direction must be stopped, and while the horse is still light and collected the forehand will be carried over as far as is necessary for the new order of affairs, and the change of leg made by the change of aids, and the horse will lead off with the side towards which he is to traverse. 


\section{CHAPTER XV.}

VOLTES AND PIROUETTES.

THE movement of traversing in a circle is called a volte, when the forehand follows the outer circumference, and the croup is kept towards the center. As the circles decrease in size the distance to be passed by the croup is lessened, and when the croup becomes the pivot about which the forehand passes the volte becomes a pirou'ette.

The smaller the circles for the volte the lighter must be the forehand of the [176] 
horse; and in the pirouette the spurs must act strongly in collecting the forces of the croup, while the hand carries back upon the hind quarters the point of balance of the weights and directs the movement.

The spurs having collected the horse act only to steady the croup, and in the earlier lessons the outside spur will be used to bring up the outside hind-leg as the mass moves about the inner hind-leg as a pivot.

The voltes are made in exactly the same manner, and by the same means, as the changes of direction in traversing. The position of the body of the horse, with reference to the angle at each point of the circumference, must be observed, and while the forehand must be kept light, 
the croup must be allowed freedom to move upon its path, until in the pirouette it is fixed by the forces of the forehand.

If it be desired to make a pirouette from the gallop, the stride must be shortened and the forces collected between hand and legs. At some finished step of the hind quarters the forehand will be brought back to destroy the forward impetus, and as the horse rises he will be turned to the side with which he leads in the gallop. But there must be a momentary rest, and the balance must be obtained before the pirouette is made.

By a trained horse in the hands of a skilled rider all this may be done so quickly and so smoothly that the different steps may hardly be observed, and the horse comes to a rest, is turned, and put again 
in the gallop, as if by an almost continuous movement in the beat of the gallop.

But before the pirouette is attempted the horse must be made quite perfect in the voltes, to the right and to the left, first at the walk, then in the passage, and finally at the gallop. In making the volte at the gallop the horse will go about to the side with which he is leading, the forehand in the outside circle, the croup on an inner line.

In changing from the volte to one hand to the volte to the other hand, the impetus of the first must cease, and the forces of the forehand having been brought back, and the forehand carried over, the change of leg will be effected, and the horse, balanced for the new movement, will make the volte in the new direction. 
As the circles of the volte decrease in size, the spurs will collect more strongly the forces of the croup, and the hand will carry back further the point of balance, so that the forehand may be lightened.

As the movement approaches the pirouette the outside spur will gradually cease to aid in the turning, leaving the hand to carry the balanced mass about the pivot.

In the pirouette the horse takes his weight and turns upon the inner hind-leg, and the outer hind-leg is brought up in support. That is, if the pirouette be to the right the horse will turn upon the right hind-leg, and the left hind-leg will be brought up to help sustain the weight.

Although traversing and the voltes prepare the horse for the pirouette, it is well 
to give him some lessons peculiar to the movement, in the following manner. Bringing the horse parallel to a wall, so that he may not move his hind quarters away from his ground, the rider will, step by step, bring the forehand about the croup as a pivot by drawing the direct snaffle-rein, and steadying the horse with the opposite rein of the same bit. The inside heel will be kept close to the flank of the horse, and the outer heel will be used to make the outer hind-leg keep up to its place as the moving mass changes its proper position.

If the movement be around to the left, the left snaffle-rein will demand the movement, and the right snaffle-rein will steady the horse. As the forehand completes the change, the right heel of the rider will bring up the right hind-leg of the horse. 
After the horse will carry the forehand about the croup, to the right or left, with the snaffle-bit, without the support of the wall, the rider will bring him into equilibrium with the curb, and with the reins of that bit held in one hand will carry back the forces of the forehand, and turn that part, so lightened and raised, about the croup ; using the outside spur, if necessary, to govern the hind-quarters.

Of course, it rests in the discretion of the rider how far the horse shall turn before he brings his fore-feet again to the ground, and the activity of the horse, as well as his balance, must be taken into consideration in performing the pirouettes. In the true pirouette the horse goes about and faces the opposite direction, before his fore-feet come to the ground. 


\title{
CHAPTER XVI.
}

\author{
TEACHING TO LEAP.
}

My experience has taught me to differ from those who think that a generous horse objects to leaping in cold blood. A horse used as I recommend will take a positive pleasure in doing all that his rider requires of him, and as long as it is not carried on until he is fatigued, there is nothing he likes better than leaping.

I can understand how horses that are punished with the spurs or whip every time they approach a leap, acquire a horror of everything that reminds them of the tor- 
ture, and that such will face obstacles only when the excitement of the chase has obliterated from their memory all recollection of the pains that attend leaping.

So, too, a horse crippled either in forefeet or in hind quarters, will naturally avoid the exertion that must bring suffering. But a high-spirited horse does not object to leaping when it is unattended by the pain of spurs or of lameness.

1 have had horses that would leap the bar when turned loose in the school; and this year I had a young mare in training that would leap a closed umbrella or a stick held out before her.

I believe that every horse can be brought to leap willingly and quietly, even though through bad management it has acquired the habit of rushing at the leaps 
or of refusing them. After a few lessons, I have ridden a horse, that had always rushed at his leaps, over an obstacle, while the reins lay knotted upon his neck; and I have reason to believe that no wellformed horse, if properly trained, will refuse a leap that he thinks he is capable of accomplishing.

Setting aside all considerations of the pleasure in riding a horse that jumps with coolness and deliberation, there is much greater safety with such an animal than with one that springs into the air with a struggle to alight he knows not how or where.

The young horse should first be taught to step over a leaping-bar as it lies upon the ground, when he is going to or returning from the spot where his daily lessons 
are given. If the horse refuse to cross the bar, the trainer should stand upon the opposite side at the length of the leadingrein with his back to the horse, and wait until the animal satisfies himself that there is nothing sinister intended, and follows his master without being urged. The attention of the horse should not be drawn to the object, and there should be no effort to drive or to pull him over it.

When the horse will cross the bar without reluctance, it should be elevated two or three inches each day until the animal is compelled to make an effort to step over it. At this height, say eighteen inches, the bar may be taken in the lunging circles, and the horse encouraged to leap it as he approaches the bar by some word or sound that he understands. 
After his first leap on the lunge, he should be stopped, and by caresses be given to understand that he has done well.

In the early part of each general daily lesson, for the space of a week, he should be made to leap the bar upon the lunge line, at the same height, but not more than three or four times each day; and he should be made to understand after each leap that his effort has met with approval.

The bar may then be raised by degrees, two or three inches each day, until it is about three feet from the ground, and the horse should be made to leap it a few times during each lesson.

During these exercises pieces of horse-clothing and highly-colored rugs, to which the horse has become accus- 
tomed, should be placed near the bar; and, after the horse has passed them in his lunging circles without paying attention to them, they should be put upon the bar for him to leap.

In this way he may be taught to jump anything that presents itself, no matter in how questionable a shape it comes.

But all this is simply to render the horse willing to leap. It still remains for him to be taught how to do it in the best manner.

After the horse will take the leap willingly upon the lunge-line, the trainer should lead him very quietly up to the bar, and giving him his head, let him take the leap from a slow walk. Then he should be stopped as he is led up to the bar, and made to jump from the halt. 
After such a course the trainer should stand at an end of the bar, so that he may be able to detect and to correct the faults the horse may have in his style of leaping.

If the horse does not bend his fore-legs closely enough, some light taps with the whip upon the shins as he rises will cure the habit; and a few touches of the whip upon the outside of the hind-legs below the hocks will induce him to gather his hind-legs well under him.

The leading-rein should hold him well under control as he approaches the bar at a walk, or stands ready to leap; but he should have full liberty of his head as he rises, and until he has regained his footing on the other side. In this way he not only learns how to gather himself for his leap, but he must alight properly, and not 
on all four feet at once, as he might do if hurried over the bar.

If the horse will not rise for the standing leap, he may at first be assisted by the hand which holds the leading-rein, carrying back the forces of the forehand, and so lightening that part. But when no longer necessary, this assistance should be withdrawn, as the horse should learn to depend upon himself for calculating height and distance.

The horse should not be ridden over the bar until he has received these lessons, and has been taught to carry himself in equilibrium. The introductory course of instruction, as described above, having been followed, and the horse having been tanght to collect himself under the hand and legs, the horse should be ridden to the 
bar at a brisk walk, and encouraged to take a leap by a pressure of the legs, and, if necessary, a play of the bit to lighten the forehand.

When he will take the leap freely, without requiring assistance from the hand, he may be ridden at the bar in a slow, collected gallop.

In the leap at the gallop the hand should do nothing more than direct the horse and maintain the equilibrium, while the legs should be used to collect the forces of the croup for the spring, but there should be no prick from the spur. If the horse be accuitomed to depend upon assistance from the bit in rising for the take-off, he will become negligent, and will throw all the responsibility upon the rider. This must result in a disaster, for 
the horse only can judge of his own capabilities, and he should decide where to take off and with what exertion.

If the horse be in fit condition to leap, and has been properly schooled, he will not require the spur to urge him to his work, and its use may give him a distaste for jumping.

When the fore-feet of the leaping horse have touched the ground, the hand should act sufficiently to gather the horse for exactly the same speed and equilibrium as that in which he approached the leap, great care being taken not to harass or check him in his movements.

A great deal that is misleading has been written in the endeavor to establish a rule to be observed when the horse falls in leaping-some would-be authorities ad- 
vocating the use of the reins to raise the horse, while others assert that any movement upon the part of the rider will hamper the efforts of the animal. A horseman of experience should know that neither rule will apply to all cases.

If, after a fall, the horse raises his head from the ground and shows a determination to get upon his feet, any action upon the part of the rider might interfere with his intelligently directed efforts.

But if the horse lies with his head upon the ground and makes no effort, or if he struggles violently in his panic, he should receive assistance from or be steadied by the rider's hand. A word of encouragement will often rouse him to a deliberate effort if the fall has cowed him.

After the horse will take his leap in 
the gallop neatly and evenly, he should be taught to take the standing jump. I have put this the last in the mounted lessons because it is the greatest test and trial of the horse's willingness and temper. I have recommended that the leaps of the mounted horse should first be made from a walk because the impetus of even that action will induce him to go on and jump. If the first leaps were taken in the gallop, the horse would be tempted to rush at the bar; but by following the course I have here laid down the leaping with deliberation becomes a habit not to be broken in upon even in the excitement of rapid movements.

In the leap from the halt the horse should be ridden quietly up to the bar and stopped. He will then be induced to 
rise by the play of the bit, and, after he has risen as high as is necessary, the legs of the rider should be pressed in to the flanks to force the action of the hind quarters.

The head of the horse should be released as soon as he begins to rise, and as the fore-feet touch the ground the hand should gently take such tension of the reins as shall be necessary to re-establish the equilibrium.

The horse should be acclistomed to take the standing leaps without other aid from the hand than the slight play of the rein that carries back the forces of the forehand.

But in the leaps from rapid motion the hand should establish the equilibrium be. fore the horse approaches the leap, and 
should do nothing more until it aids in collecting the horse after the fore-feet have reached the ground upon the far side of the obstacle.

In riding a horse at a broad leap the speed must be great enough to give him the advantage of the impetus of his motion, but the speed must not be so great as to prevent him deciding upon where he should take off and with what exertion. If driven hard at a broad leap the horse will often become disheartened or confused and unable to control his powers.

A horse should never be ridden at a high leap in a speed that prohibits him being collected; and the horse is capable of his greatest effort in this direction in a very slow, collected gallop. 


\section{CHAPTER XVII.}

GENERAL NOTES.

A HORSE with any of the following defects is unsuitable for use under the saddle:-A straight shoulder; a ewe neck; turned-in toes ; corns, or any injury or disease of the feet; defective vision; round joints, bent knees, or other evidences of weakness in the legs; action that wears away the shoe at the toe.

This list might be greatly increased, but I have named the faults that are common and most likely to render the animal dangerous to ride. If the horse have a 
straight shoulder, turned-in toes, or action that wears away the toe of the shoe, he will not be sure upon his feet. If he have round joints, bent knees, or other signs of weakness in the legs, he will fall at very slight provocation. Should he suffer from corns or other diseases of the feet, he may be apparently sound and safe in his action, and yet liable to drop to the ground as if shot, to the peril of his rider's neck. With defective vision he will be shy of passing unusual objects; and with a ewe neck he will carry his nose in the air regardless of treacherous paths.

Some of these faults may, to a certain extent, be remedied in training, but natural defects cannot be wholly overcome, and all horses that have any of those mentioned may safely be shunned. 
A nervous man cannot hope to have any success with horses. I do not, by this, make reference to the well-known fact that a horse will assume the mastery of a timid rider, but I mean to say that if the trainer is lacking in the composure necessary to establish a confidence in the horse, his labor will be vain and the horse will become shy and suspicious.

The reason for this effect upon the horse is that in any unusual position he depends upon the man for encouragement, but if he finds that the rider is disturbed the animal will think that there is something wrong, and will be ready to take alarm at anything that his quick imagination clothes with danger.

It is a common case for a rogue of a horse to play the tyrart with a timid rider, 
by making a pretense of being frightened at everything that can attract his attention, until he sometime or other overdoes his acted part and finds that he is running away in earnest, when he becomes terror-stricken, and the farce becomes a tragedy.

Undoubtedly, much of the vice in horses has been cultivated by the severity and cruelty of their masters, and it is true that vice may often be cured by care and kindness. But there is not in the heart of the horse that true love for man that the dog, even when neglected and illtreated, always bears for the one he acknowledges as master.

The horse, therefore, may not be governed by love; he must be made to feel and to acknowledge the superior pow- 
er of man. This superior power must be asserted through kindness and firmness; either extreme of harshness or of indulgence will render the horse vicious, and destroy the influence of the man over the animal.

It is astonishing how much courage a horse will receive from a cool and determined rider, but the boldest horses become timorous at unusual sights and sounds when they do not feel the support of a steady hand. In time the horse may be brought to face the most appalling objects, and his confidence in man grows with each escape from suspected danger.

But it is when this nervous, excitable animal is roused by the stir and clang of battle that he banishes all fear, and even takes a delight in the perilous game of 
war. With a spirit that seems heroic, he will eagerly plunge into the thickest of the fray, and, unmindful of the horrid hail of missiles, bear his rider to death or glory.

The next day, perhaps, he trembles as he is made, unwillingly, to pass the harmless body of some poor beast lying in the battery he so gallantly charged in the fight. All horses should be taught to bear the spur without flinching. This w:11 prove a great safeguard to the rider, as the horse will not bolt at the prick of the rowel, and will be rendered quick to obey the will of his master.

It is not necessary to use a sharp spur upon a schooled horse, as his training will render him so quick and ready that he will answer to the pressure of the leg without waiting for the severer form of 
the aid, and a blunt spur will be all that is required should he hang back a little at times. But it is first necessary that he should submit to the application of the sharp rowel without either bolting or showing resentment. Horses of even the most nervous temperament may be taught to submit to the spur after a few lessons given in the following manner:-

While at the walking pace the rider will gently press his unarmed heels against the sides of the horse, and restrain increased speed or restlessness by a light hand and soothing words. When the horse will suffer the pressure of the heels without making an effort to go beyond the limits placed by the hand, the rider will, in the same way, accustom the animal to the application of the spur. 
This use of the spur renders the horse very docile and steady, and the sharp spur may be superseded by the blunt rowel, so that the aid shall not have even the appearance of cruelty.

Many horses are dangerous to a spurred rider until they have been trained to the sharp rowel in this or in some similar way. And no horse is under proper control until he will bear the spur without trying to force the hand.

The spur should never be delivered by a thrust or kick, but by carrying back the leg until the rowel touches the flank of the horse, and applied with such force as is necessary by lowering the toe.

The spur may in this way be given with all required celerity, and without throwing the horse out of his balance, 
rousing his resentment or discomposing him by the rudeness of the attack.

A perfect seat may only be obtained by riding without reiris or stirrups.

Otherwise, the rider will acquire the habit of depending, more or less, upon the aid of bit and irons. If he cannot ride without their support, he will be unable to use his hands and legs in the management of his steed; and he will be a clog rather than a help to the horse; for his hand will check and harass the forehand, while his seat, forced by the weight he bears in the stirrups, will not permit the body to keep the poise required for the balance of the mass.

I do not think that too much importance can be given to lunging upon the cavesson. I know of nothing that will so 
effectually quiet an unruly or a nervous animal, and it greatly improves the action and movements of the horse.

After the horse has passed about the trainer several times at the length of the rein, he should be induced to come up to the man to be caressed and encouraged, and then made to pass about in the opposite direction, to be again brought up to the man.

A few lessons given in this way will give the most timid horse a confidence in his trainer that can be produced by no other means with which I am acquainted, and to obtain the confidence of the horse is the first and longest step in his subjugation.

As the rules I have laid down for obtaining control over the horse should 
prepare the reader for every emergency, I have not thought it necessary to cite particular cases, or to draw the attention from more important matters to the narration of anecdotes or the relation of personal adventure. 


\section{CHAPTER XVIII.}

WHEN LADIES RIDE.

AlL the instructions contained in these pages, except so far as regards those for gymnastics and for the seat, will apply to ladies, when the whip will take the place of the right leg of the man.

The whip should be strong and straight, and the horse will be trained to answer to its application in exactly the same way as to the pressure of the man's leg.

It is only necessary to say a few words about the seat. I have nothing to sug[208] 
gest in a saddle by a good maker, beyond advising that it be made to fit the rider, and that, in addition to the double safetystirrup, the leathers should hang from spring-bars in the tree, the bar inclining upwards from the front.

The lady should so sit upon the horse that her weight will fall perpendicularly to the back of the horse; her face directly to the front, her shoulders drawn back, and her elbows held to her sides. She will permit her body, from the hips upwards, to bend with the motions of the horse, in order that she may preserve her balance. The reins are to be held in the manner prescribed for men, the hand in front of the body, and in a line with the elbow. The whip is to be carried in the right hand, with the point towards the 
ground. The horse should never be struck with the whip upon the head, neck, or shoulder. To apply the aid upon those parts will teach him to swerve, and render him nervous at the motions of the rider. In a lady's hand the whip simply takes the place of a spur for the right side.

The horns of the saddle, the superfluous one at the right being dispensed with, should be of such lengths and curva. tures as will suit the rider.

The right leg will hold the upright horn close in the bend in the knee, by such a pressure as the action of the horse or other circumstances will dictate.

The left foot will be thrust into the stirrup to the ball of the foot, and the heel will, as a rule, be carried down; but when the heel is elevated the upper part 
of the left knee should find support in the side-horn, and for that end the stirrupleather will be given such a length as will permit this. By the grasp given by the elevation of the left knee from the stirrup and the embrace upon the upright horn by the right leg, the rider will have as strong a seat as her strength can afford; and with a proper balance she will not be likely to find a horse that will unseat her. As a fall of the horse is attended with great perils to a lady rider, she should never be mounted upon an animal whose legs betray any weakness, or whose knees give evidence of stumbling, or upon one that is not master of her weight. The lady must see that, in turning to the right or left, her horse leads on the side to which he bends, and she should carry her 
inside shoulder slightly back at the same time, so that the center of gravity of the mass will be preserved. The leg will support the horse in turning to the right, the whip will give support in turning to the left.

The lady who desires to excel in horsemanship should, when an opportunity offers, witness the performance of some school-rider of her sex. A few public lessons from such mistresses of the art as Mademoiselle Guerra or Mademoiselle Elise de Vienne, will be of very great advantage. 


\section{GLOSSARY AND INDEX.}

Action, ror. $\quad \mathrm{CADENCE}$ (continued).

Backing, I2I ; at a trot. I22; there are two cadences, one, mounted lessons in, I24; at when the two fore-feet come a gallop, 154 .

Balance, 36 ; exercises for, 45. BARS, the bare gums of the horse between the grinders CANTLE, the rear part of the of the upper parts of the saddle that fits over the jaws and the tceth of the back of the horse. mouth proper.

CAVESSON, a head-stall fur-

Bcaring on the hand, 58 .

BIT, when used alone denotes the curb or lever bit.

Bits, the, 27, 89: resistance to, III; in backing, I $2 \mathrm{I}$.

Bolting, 79, 79 . to the ground, the other, when the two hind-feet come to the ground.

nished with a jointed noseband of metal, to which are attached rings for the lungeline.

Cavesson, The, lunging upon, 205.

BRANCHES, the lower arms Children's riding, I2. of the curb bit to which the Circling, after, I3r. reins are attached.

Contests, 22.

CADENCE, the beat or mo-Correcting defects, 93. mentary rest that occurs in Correction, 22.

a finished stage of a gait. Courage, dependent on the For instance, in the gallop rider, 199; in battle, 201. 
CROUP, the top of the back|EQUILIBRIUM (continued). of the horse where the brium is maintained in mohaunches join the body. Used also to designate the hind-quarters of the horse. CURB-CHAIN, the chain that passes beneath the chin of the horse from the eyes of the cheek-pieces of the curbbit.

Curb, The, description of, 27 ; holding, 39, 56, 102 ; in Equipments, 26. walking, I06; contrasted EWE-NECK, a name given with the snaffle, I 2 .

Descents, 64, 84 .

Direction, changes of, 39,54 , $60,103$.

DIRECT Rein or Spur, the rein or spur on the side to which the horse is bent, or is to make the increased action.

Dismounting, 50. tion by the advance of the forces of one extremity, followed by those of the other, in a constant effort to establish a point of union and balance.

Equilibrium, 59, 62 : in trotting, 64,65 ; in leaping, 73 ; 89,$90 ;$ how obtained, 94.

Equipments, 26 when a horse has a depression in the neck immediately in front of the withers.

Exercises, for the seat, 43 ; for the balance, 45 ; for the legs and feet, 47 ; general $5 \mathrm{I}$.

Falls, in leaping, I92 ; causes of, 198.

Faults, 77 .

Fear, 24.

DOUBLE-BRIDLE, the bri-FORCES, the weights and dle fitted to receive both the curb and the snaffle bits.

Double-bridle, 56 ; first lessons, 56 ; 102.

Education, 21 .

EQUILIBRIUM, the state of balance between the forces of the forehand, carried back by the bit, and of the croup, brought up by the spurs. The aproximate equilipowers of either extremity of the horse.

FOREHAND, that part of the horse in front of the saddle. Gallop, The, 67 ; position, 67 ; true in, 67 ; turning, 68 ; to put a horse into, 69 ; in equilibrium, I Io ; backward, I22; after changes of leg in, I3I; changes in the, I39; leading in, I39; false in, 
Galop, The (continued).

I39; disconnected in, I39; method of producing, 140 ; in military riding, $\mathrm{I} 4 \mathrm{I}$; the old method, I42; changes in, I43; to halt from, I 47 ; I48 ; in place, 150 ; preliminaries, $15 \mathrm{I}$; to back at, 154 ; to move orward at, 155 ; traversing at, 172 .

General exercises, $5 \mathrm{I}$.

Getting into place, $3 \mathrm{I}$.

Grasp, 37.

Halting, 55; from a walk, Ior, 147 ; from a trot, $\mathrm{I} 47$; from a gallop, 148 .

Hands and legs, 53.

HAUTE ECOLE, LA, the high school of riding in the movements of the manége.

HIND-QUARTERS, that part LUNGING, exercising the of the horse behind the sad- horse in circles about the dle.

Horse gymnastics, 42.

Horses, how to use, 2 I.

Kicking, 32.

Ladies, instructions for, 208 ; whip, 208; saddle, 209; stirrup, 209; seat, 209; use of whip, 210; saddle for, 210; Martingales, 27; advantages horses for, 2 II ; position in and disadvantages of, 29. turning, 2II ; lessons for, Mounting, method, 31 ; disad212.

Leap, The, 72 ; standing, vantages of usual method, $33 ; 48$.

72; flying, 73 ; speed, when Movements in place, after, I3I. 
Movements, quietness in, r37.|PIROUETTE (continued).

Nervousness, I99.

Obedience, $6 \mathrm{I}$.

Obstinacy, 23, ro4. as the pivot, the movement is called the reversed firou. ette.

OPPOSITE Rein or Spur, the Pirouettes, I43, 172, I76; from rein or spur opposite to the the gallop, I78; before atside to which the horse is bent, or is to make the increased action. tempting, $179 ; 180 ;$ lessons in, $18 \mathrm{I}$.

PASSAGE, a trot in which the legs diagonally disposed step together, in an action not so high as the Spanish step.

Passage, The, 127 ; method of producing, I28 ; traversing Rearing, $78,80$. in, 165 ; method of traversing in, 165 .

PATHS, the lines followed by the feet of the horse in any movement.

Pawing, 33.

Piaffer, The, $\mathrm{r} 32$; teaching, I32; its use, $\mathrm{r} 33$; its diffi culty, $\mathrm{I} 33$; to back at, $\mathrm{I} 36$; means for producing the movement, 136 .

PIROUETTE, the movement in which the horse, supporting himself upon the hind Riding, requisites for excellegs, turns about, the inner lence in, 13 ; learning from hind-leg acting as the pivot.

When the horse carries the croup about the forehand, POMMEL, the bow or front part of the saddle, that fits over the withers of the horse.

PORT, the bend in the mouthpiece of the curb-bit made to receive the tongue of the horse.

Reins, The, 39 .

RESISTANCES, the opposition that the rider finds in demanding any movement from the horse; these may be active, or by the will of the horse; passive, or due to the weights and conformation of the horse. The first are corrected by the curb-bit and the spurs, the latter by the snaffle and the spurs.

books, 15 ; personal instruction in, 16 ; instructions for ladies in, 208 .

the outside fore-leg acting Rising in the trot, $6_{5}$. 
ROWEL, the sharp wheel of Spur, The, $2 \mathrm{I}$; governing the the spur.

Saddle horses, defects in, 197 : for ladies, $21 \mathrm{I}$.

Saddle, The, description of, 26 ; for ladies, 209.

School system, The, defense of, 7 : object of, 9 : objections to, answered, I0; Stirrups, 27; short, 37; for safety secured by, I3. trot, 65,90 ; not an instrument of punishment, I05 ; in pirouettes, II 8 ; horses should be taught to bear. 202 ; blunt, 202 ; lessons in the use of, 203 ; method of applying, 204 .

Seat, The, 34; obtaining, 35 ; Stumbling, 63 ; causes of, $s_{3}$, stability of, 36 ; exercises 198 .

for, 43; how to obtain a per-Suppling the croup, II3.

fect seat, 205; a lady's, 209. Suppling the forehand, 98.

Severity, uselessness of, I04. Trained and untrained horses Shying, 8I : cause of, 198 . contrasted, 96 .

Snaffle, The, 27, 39; holding, Training, 7, 21; necessity for, $39: 53,56,98$; in walking, 106: contrasted with the curb, II2.

SPANISH TROT, a trot in which the legs diagonally disposed move togrether in very high and brilliant action, with momentary rests between the strides. 92: remedying defects by means of, 93.

TRAVERSING, the movement of the horse to either side, his fore-legs following one path, his hind-lerss slightly in rear, upon a parallel path. Spanish trot, The, 65, $158 ; 143$; in the passage, 165 ; method of producing, 158 ; importance of, 165 ; method an exaggerated passage, 161 . of, 166 ; change in, 170 ; at Speed, not decreased by school training, Io; to measure, 54 ; to increase, $54 ; 55$; to TREAD of the Stirrup, that increase, $6 \mathrm{I}$; to moderate, part upon which the sole of $6 \mathrm{I}$; to increase, 97 ; to the foot rests. moderate, 97 .

Tricks, 77. 
Trot, The, 63 ; of the manége, |Volte, The, I72, 176 ; method, 65 ; Spanish, 65; rising to, 177 ; at the gallop, 179 ; 65 ; in equilibrium, Iro; changing, 179. backward, 122 ; methods of Walk, The, 63, 99 ; instruction producing the Spanish trot, in, Io6. I58.

Weight, 36.

Vices, 77 ; increased by sever- Whip, The, 21 ; not an instruity, 200.

VOLTE, the movement in which the horse traverses in a circle, the croup towards WITHERS, the elevated ridge the center. When the forelegs follow the inner circle it is called a reversed volte. ment of punishment, I05 ; for ladies, 208; use of, by ladies, 2 IO.

on the horse's back at the junction of the neck with the body. 

Wabter Family Library of Veterineny Mane

Chanmings School of Veterinary Alediche of Tưts University

200 Westboro Road

Nomti Gratton int 195 

